\title{
Paisajes rupestres. La identificación de patrones de producción y distribución de arte parietal en escalas espaciales amplias (Cañadón Yaten Guajen, Santa Cruz, Patagonia argentina)
}

(1) Dánae Fiore" y Agustín Acevedo**

Recibido: 30 de mayo de 2017

Aceptado: 15 de septiembre de 2017

\section{Resumen}

En este trabajo se presenta una primera aproximación a la caracterización de los paisajes rupestres mediante la exploración y análisis sistemático del arte rupestre de dos sectores del cañadón Yaten Guajen (Santa Cruz, Patagonia Argentina). Dicho análisis se basa en la concepción de que los paisajes rupestres actualmente visibles son producto de las acciones acumuladas de grupos humanos cuyas agencias dejan señales en: a) la distribución de motivos en el soporte rocoso-identificables mediante el estudio de su frecuencia, proporción, densidad, expansión y variedad de motivos y de tipos de motivos- y b) el vínculo de los motivos entre sí y con el soporte. Para ello se propone una metodología de registro y un protocolo de análisis de datos rupestres a escalas espaciales amplias, combinando la noción de registro arqueológico como un continuum y la noción de que la experimentación de los paisajes rupestres requiere tanto percepción como movimiento y opera a distintas escalas espaciales complementarias. Los resultados se discuten a la luz del vínculo entre agencia de productores y observadores del arte, sugiriendo que los paisajes rupestres requieren no solo percepción visual sino también movimiento físico para poder experimentarlos.

Rock art landscapes. Identification of rock art production and distribution patterns at broad spatial scales (Yaten Guajen Canyon, Santa Cruz, Patagonia argentina)

\footnotetext{
Abstract

This paper presents a preliminary approach to the characterisation of rock art landscapes based on the study and systematic analysis of rock art in two sectors of Yaten Guajen Canyon (Santa Cruz, Patagonia Argentina). This analysis is based on the notion that rock art landscapes which are currently visible are product of the accumulated actions of human groups whose agencies have left signs in: a) the distribution of motifs on the bedrock -identifiable through the study of the frequency, proportion, density, expansion

\section{Palabras clave}

Arte rupestre

Paisaje

Escalas espaciales amplias Agencia

Percepción

Movimiento
Keywords

Rock art Landscape Broad spatial scales Agency Perception Movement 
and variety of motifs and motif types-, and b) the relations within motifs, and between motifs and the bedrock. To this end, we propose a rock art recording method and data analysis protocol which operates at large spatial scales, combining the notion of the archaeological record as a continuum with the notion that the engagement with rock art landscapes requires both perception and movement while operating at different complementary spatial scales. The results are discussed in the light of the links between the agencies of rock art producers and observers, suggesting that rock art landscapes require not only visual perception but also physical movement to experience them.

\section{Introducción}

El objetivo principal de este trabajo es contribuir a la discusión del vínculo entre arte rupestre y construcción de paisaje, mediante el análisis sistemático de la distribución de motivos grabados y/o pintados sobre soportes rocosos a escalas espaciales amplias. $\mathrm{Su}$ objeto es identificar patrones de distribución de arte sobre soportes rocosos no transportables que permitan dilucidar aspectos de la agencia humana subyacentes a la creación de paisajes rupestres. Con el término "paisaje rupestre" nos referimos a la construcción cultural de un paisaje visual en el que operan de forma combinada los elementos del paisaje natural -geoformas, topografía, tipos de roca soporte, cursos de agua, vegetación, etc. - y el emplazamiento de imágenes producidas sobre los soportes rocosos seleccionados. Continuando con la línea de investigación propuesta en publicaciones anteriores, en este trabajo se propone que la visibilidad arqueológica de los paisajes rupestres puede analizarse a partir del estudio sistemático de la distribución de las imágenes en los soportes rocosos -frecuencia, proporción, densidad, expansión y variedad de motivos y de tipos de motivos- y de los vínculos de los motivos entre sí $y$ con el soporte donde han sido emplazados -tipos de motivos, sus combinaciones en la composición plásticas de paneles, sus técnicas de ejecución y sus emplazamientos en las distintas morfologías de topografía del soporte rocoso (Acevedo, Fiore y Franco, 2013; Acevedo, Fiore, Franco y Ocampo, 2012-2014; Aschero, 1997; Fiore y Ocampo, 2009; Hernández Llosas, 2009; ver discusión más abajo).

Esta noción de paisaje rupestre es aplicada al estudio del arte rupestre del cañadón Yaten Guajen de la región Margen Norte del Río Santa Cruz (MNRSC), caracterizado por la creación de imágenes plasmadas sobre rocas que se encuentran distribuidas a lo largo de varios kilómetros (Acevedo et al., 2012-2014, 2013; Fiore y Acevedo, 2016; Fiore y Ocampo, 2009). En tal sentido, como argumentaremos en este trabajo, el cañadón Yaten Guajen muestra una distribución de arte rupestre que por su amplia extensión y continuidad en el espacio desafía la noción y escala de "sitio", para plantearle a los investigadores la necesidad de emplear escalas espaciales más amplias en sus registros y análisis. A su vez, dicha distribución es interpretable como una señal arqueológica que evidencia la acumulación de actividades humanas de producción rupestre a lo largo de un espacio, que implicó no solo la selección del emplazamiento, la producción y visualización de motivos en un panel específico del soporte, sino también la movilidad física entre paneles para aproximarse a percibir el paisaje rupestre en su conjunto. Para ello, se revisan y discuten conceptos relativos a la noción de paisaje en arqueología, para luego proponer una metodología de registro y procesamiento de datos que permita el análisis sistemático de información sobre paisajes rupestres. Así, este análisis arroja nueva luz sobre las formas en que los productores y observadores del arte se vincularon con el soporte rocoso y con las imágenes rupestres al momento de crearlas y posteriormente en su percepción a distintas escalas: como composiciones dentro de paneles y como elementos de paisajes rupestres. 


\section{Marco teórico: el arte como elemento de construcción de paisajes rupestres}

La noción de paisaje en arqueología ha sido concebida y discutida desde numerosos marcos teóricos (Anschuetz, Wilshusen y Scheick, 2001; Gkiasta, 2008; Parcero Oubiña, Criado Boado y Barreiro, 2014; entre otros). Interesantemente, la definición original del normativismo histórico-cultural no se centró en el concepto de paisaje, sino en el de espacio, concebido como algo externo a un grupo humano, operacionalizado en la escala de región como aquella relevante para identificar la distribución espacial de una fase/período cultural (e.g. Willey y Phillips, 1958). Dentro de este marco teórico el estudio espacial del arte rupestre se orientó a los análisis estructuralistas intra-sitio y a la búsqueda de repeticiones de patrones de combinación de motivos para la definición de estilos regionales (e.g. Leroi-Gourhan, 1967).

La arqueología procesual produjo numerosos cambios en la forma de abordaje del análisis espacial. Por una parte, dado que su eje teórico se centró en el análisis de las estrategias adaptativas de los grupos humanos al ambiente, el paisaje fue concebido principalmente como una fuente de recursos naturales bióticos y abióticos a ser explotados mediante dichas estrategias (e.g. Butzer, 1982). Por otra parte, el despliegue de dichas estrategias llevó a algunos investigadores a ampliar la escala espacial de análisis saliéndose del "sitio" para a) estudiar las fuentes de recursos explotados en distintos puntos del espacio mediante métodos tales como el "site catchment analysis" (Vita Finzi y Higgs, 1970) y b) concebir al registro arqueológico como un continuum cuyo estudio es abordable mediante la arqueología distribucional (e.g. Dunnell y Dancey, 1983; Foley, 1981). Dentro de este marco teórico surgieron los primeros análisis de arte rupestre netamente centrados en el vínculo de la producción artística con el paleoambiente (Jochim, 1983), así como aquellos vinculados a conceptos más culturales, tales como el de geografía social (Conkey, 1984) o la distinción entre sitios públicos y sitios privados (Schaafsma, 1985).

El procesualismo fue fuertemente criticado por el post-procesualismo especialmente por su concepción del paisaje como neutral y externo a los grupos humanos, ya que al concentrarse en los aspectos naturales y materiales del mismo, no dio importancia a las cuestiones subjetivas del vínculo entre personas y paisaje -su percepción, su valoración, su simbolización- (e.g. Ingold, 1986; Ouzman, 1998; Tilley, 1994). Así, el postprocesualismo enfatizó que el paisaje implica un vínculo subjetivo de experimentación, apropiación, memoria, movimiento, etc. con espacios no-neutrales que, según estos distintos procesos, se convierten en lugares. Este marco teórico también generó sus propias interpretaciones del arte rupestre como parte constitutiva del paisaje, ligadas a una aproximación inicialmente hermenéutica y luego fenomenológica (Tilley, 1991, 1994; Tilley y Bennet, 2008).

El post-procesualismo ha sido principalmente criticado debido a que muchos de esos elementos tienen, por su naturaleza subjetiva, una baja visibilidad arqueológica. A ello se suma que "ha sido acusado de ser muy especulativo..., negligente con los datos y evidencia, o faltante de una metodología sólida" (Parcero Oubiña et al., 2014, p. 4381). Es por ello que algunos autores, tanto desde el post-procesualismo como desde enfoques de arqueología social, han enfatizado la necesidad de desarrollar estudios de índole sistemática que permitan identificar patrones específicos en la materialidad del arte rupestre, que habiliten caracterizaciones solidas de la forma en que las imágenes construyen al paisaje en general y a lugares específicos que lo constituyen en particular (e.g. Bradley, Criado Boado y Fabregas Valcarce, 1994; Carden, 2008; Criado Boado y Penedo Romero, 1989; Domingo Sanz, Fiore y May, 2008). Estos enfoques de índole social destacan que la agencia de las personas productoras de cultura material incluyendo el arte- es rastreable por lo menos en parte mediante el estudio de las 
1. Numerosos autores han contribuido a la definición y discusión de cada una de éstas variables, entre otros: Bednarik, 2001; Fiore, 2006; Hernández Llosas, 2009; Rosenfeld, 1988. señales que los agentes han dejado repetidamente en los propios artefactos (Dobres, 2000; Gell, 1998). La agencia social puede definirse como la capacidad de las personas de actuar en el mundo como agentes, que son a la vez estructurados por las prácticas previas y simultáneas a ellos y estructurantes de las prácticas presentes y futuras, produciendo mediante éstas efectos concretos sobre la cultura material (Bourdieu, 1977; Giddens, 1979). Estos productos de cultura material -tales como el arte rupestre- no solo preservan rastros reveladores de dicha agencia, sino que también ejercen efectos sobre posteriores personas que interactúen con los objetos/imágenes artísticos (Dobres, 2000; Gell, 1998).

Así, es posible sostener que el arte rupestre ha sido un elemento activo en la construcción y percepción de paisajes visuales por parte de las sociedades que lo produjeron (en el caso que nos ocupa, sociedades cazadoras-recolectoras) y también para poblaciones posteriores que entren en contacto con las imágenes (buscándolo/encontrándolo, transitándolo, visualizándolo, etc.). Esto es especialmente relevante para el arte que se emplaza en soportes al aire libre tales como paredones o bloques, y también en aleros, ya que todos ellos ofrecen soportes visibles mediante el movimiento frente o alrededor de ellos, sin necesidad de la acción de "entrar" como en el caso de las cuevas, acción que limita necesariamente el campo visual y segmenta por lo menos parcialmente al interior de la cueva respecto del resto del paisaje. Estos paisajes rupestres se caracterizan por una serie de variables, incluyendo: a) el rango de variabilidad formal del repertorio de tipos de motivos; b) la frecuencia, expansión y densidad de motivos emplazados a lo largo del soporte; c) las elecciones de emplazamiento de ciertos tipos de motivos en ciertos tipos de topografías del soporte según su morfología -cueva, alero, paredón, bloque- (la repetición de estas elecciones genera, a su vez, patrones de asociación entre tipos de motivos y topografía y patrones de combinación reiterada del mismo tipo de motivo en un mismo panel); d) la combinación de tipos de motivos en un mismo panel, generando imágenes compuestas por dos o más tipos de motivos; e) el uso de técnicas de producción específicas, que generan contrastes y texturas específicos que afectan la percepción visual de los motivos; f) el vínculo entre las técnicas, el tipo de soporte rocoso -según su dureza y granulometría- y la disponibilidad de fuentes potenciales de pigmentos; g) el vínculo entre las técnicas de producción, la morfología de la topografía y el reparo potencial ofrecido por ésta -tomando como principio general que en soportes al aire libre o semi-expuestos, bajo las mismas condiciones ambientales y topográficas, generalmente la pintura tiene comparativamente menor capacidad intrínseca de preservación diferencial que los grabados ${ }^{1}$; y h) la visibilidad de las imágenes una vez emplazadas en el soporte.

Todos estos elementos, que separamos aquí con propósitos analíticos, han operado de manera integrada en el pasado y resultan de la forma en que las personas se han vinculado con el soporte rocoso y su espacio circundante a través de la percepción, el pensamiento, el afecto y la práctica -transitándolo, habitándolo, experimentándolo y transformándolo-. En dicha transformación práctica se incluye la creación de imágenes que marcan visualmente al soporte, construyendo un paisaje rupestre (Acevedo et al., 2012-2014, 2013; Aschero, 1988, 1997; Carden, 2008; Conkey, 1984; Criado Boado y Penedo Romero, 1989; Fiore, 2016; Fiore y Ocampo, 2009; entre otros).

Ahora bien, resulta crucial tener presente que, así como no todas las imágenes producidas en el pasado se han conservado hasta el presente, tampoco todas las imágenes que se registran en el presente fueron producidas simultáneamente en el pasado. El arte rupestre es un fenómeno aditivo (Aschero, 1997), razón por la cual en el análisis de los paisajes rupestres es relevante distinguir entre dos clases de patrones:

1) los patrones que relacionan a tipos de motivos específicos con su emplazamiento topográfico son válidos para cualquier momento de la producción rupestre porque 
vinculan a cada tipo con cada morfología topográfica independientemente de que haya existido una acumulación de nuevos tipos en el mismo panel a lo largo del tiempo. Denominamos a éstos como patrones no-relacionales (Fiore, 2016), ya que dependen exclusivamente del vínculo unívoco entre el motivo y la topografía, sin depender de otros motivos que pueden -o no- estar asociados en la misma composición visual del panel;

2) los patrones que relacionan a tipos de motivos entre sí formando parte de una composición visual dentro de un panel, son a priori válidos solamente para los últimos momentos de la secuencia arqueológica, ya que los repertorios y combinaciones iniciales de tipos de motivos pueden haber sido alterados mediante adiciones posteriores de nuevos tipos a lo largo del tiempo, por lo cual, si estas adiciones son recurrentes, se generará un nuevo patrón que será identificado arqueológicamente ${ }^{2}$. Denominamos a éstos como patrones relacionales (Fiore, 2016), ya que su construcción e identificación depende directamente de las relaciones entre los tipos de motivos combinados en un mismo panel.

Tal como indican Parcero Oubiña et al. (2014), las corrientes teóricas que proponen una visión social y no-neutral del paisaje, requieren de una aplicación metodológica rigurosa y sistemática que sea adecuada para poder fundamentar empíricamente la existencia de procesos de apropiación y percepción del paisaje por las sociedades del pasado, para evitar que queden en el mero enunciado conceptual y abstracto. En tal sentido, la metodología aquí propuesta se centra en generar formas de registrar y procesar datos relativos a la distribución de imágenes rupestres a lo largo de soportes rocosos que exceden la escala de sitio debido a que sus largas extensiones no permiten señalar con claridad los límites entre un sitio y otro (ver detalles sobre el caso de estudio en la próxima sección). Esta metodología distribucional ha sido concebida para generar un panorama inicial sobre la distribución del arte rupestre en escalas espaciales amplias, permitiendo registrar y evaluar la frecuencia, proporción, densidad, expansión y variedad de motivos, caracterizando así los paisajes rupestres que se despliegan a escalas supra-sitio. Interesantemente, muchas de estas tendencias no son perceptibles mediante la visualización de un único panel o incluso de varios paneles con arte rupestre, sino que emergen a partir del registro y evaluación del comportamiento de las variables que subyacen a la construcción del paisaje rupestre que operan a escalas espaciales amplias. En estos casos, dado que la distribución de las imágenes ocurre a lo largo de soportes distantes en el espacio -que impiden una visualización y comparación desde un único punto de vista- la apreciación cualitativa y cuantitativa de estos patrones potenciales requiere necesariamente de circular físicamente por el espacio para visualizar y registrar las imágenes desde numerosos puntos de vista sucesivos en el espacio. Así, la recolección de la información (y su posterior procesamiento) debe efectuarse en escalas acordes con las del paisaje bajo estudio, que exceden la de "sitio". Es aquí donde la noción de registro arqueológico como un continuum arriba mencionada resulta relevante, en tanto que sirve para pensar al registro arqueológico de arte rupestre desde una perspectiva distribucional, que permita abordar a los paisajes rupestres integrando información sobre la distribución y emplazamiento del arte a distintas escalas espaciales articuladas entre sí -transecta, unidad topográfica, panel, motivo-. Esta metodología de trabajo ha sido aplicada al caso del cañadón Yaten Guajen (región MNRSC).

\section{La región bajo estudio: características y antecedentes}

La región Margen Norte del Río Santa Cruz está ubicada en la porción sur de la provincia de Santa Cruz, desde el río Leona al Oeste hasta el Océano Atlántico al Este (Patagonia, Argentina) (Figura 1). Está caracterizada por una serie de cañadones que corren transversalmente al curso del río, con una dirección predominante NorteSur. Estos cañadones tienen extensiones variables, desde $29 \mathrm{~km}$ (ej. El Lechuza) hasta
2. La existencia de momentos distintos de conformación de patrones puede ser distinguida mediante el estudio riguroso de pátinas, obliteración de colores y superposiciones, pero éstos indicadores no son siempre fiables ya que no siempre son diagnósticos de reales diferencias diacrónicas y pueden responder a cuestiones de otra índole como sesgos diferenciales de conservación, por lo cual requieren de un control tafonómico que no ha sido aún desarrollado en la región bajo estudio (e.g. Bednarik, 2001; Rosenfeld, 1988). 

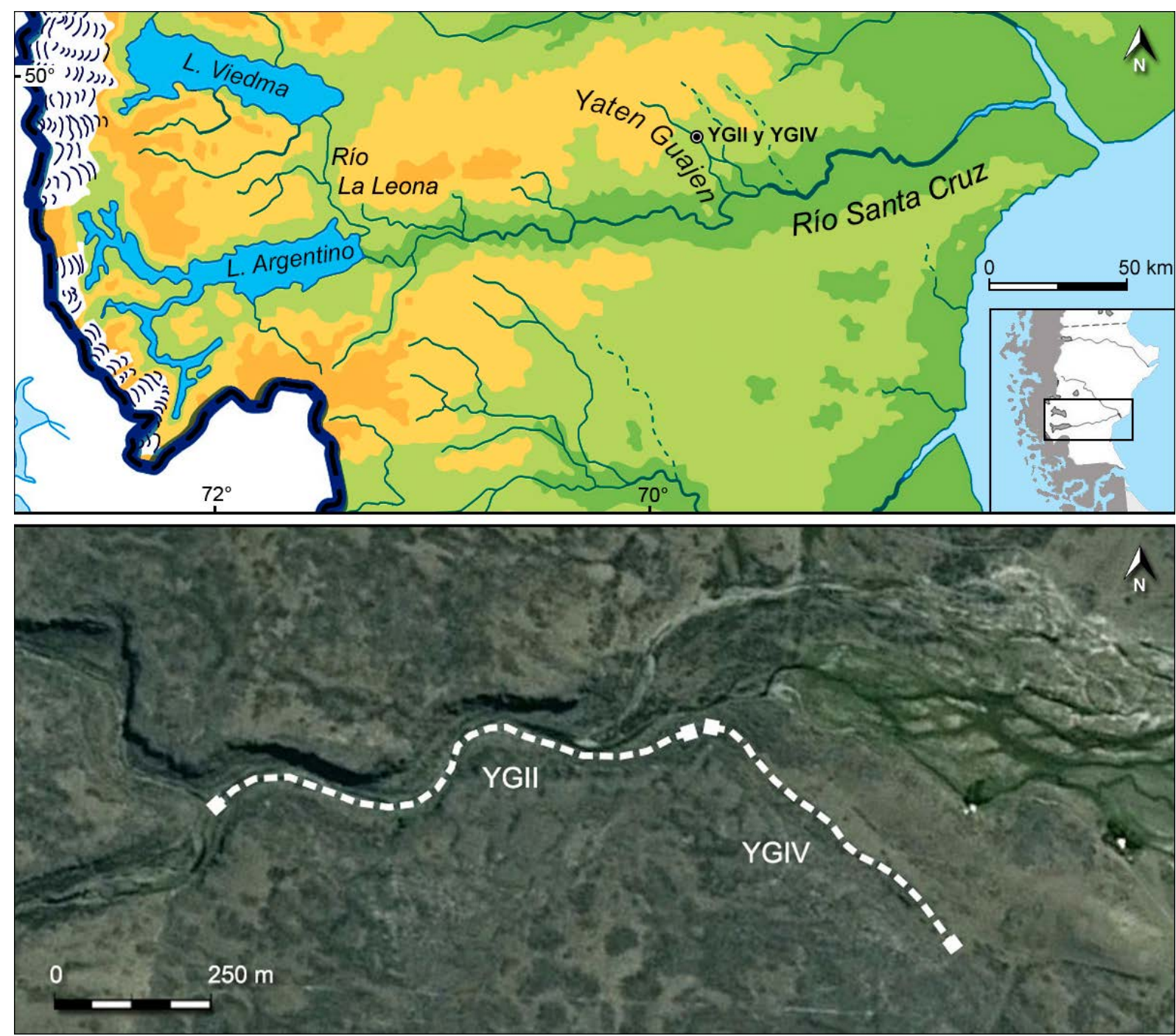

Figura 1. Provincia de Santa Cruz (Patagonia, Argentina). Localización de la región MNRSC, cañadón Yaten Guajen y sectores YGll y YGIV dentro del mismo.

3. Molina definió la siguiente secuencia en orden diacrónico: 1 ) “estilo de marcas", 2) "estilo de combinación", 3) "estilo de grabado fino" y 4) "estilo de pisadas". De estos "estilos", solo el cuarto ha sido detalladamente definido e identificado en términos de su repertorio, técnicas y distribución en Patagonia (Gradin, Aschero y Aguerre, 1979; Menghin, 1957; etc.). aproximadamente $65 \mathrm{~km}$ de largo (ej. Yaten Guajen), y están compuestos principalmente por rocas básicas alcalinas de grano fino, con superficies irregulares, y un gran número de bloques dispersos, de tamaños medianos a grandes (Panza y Franchi, 2002).

La existencia de arte rupestre en esta región fue informada por primera vez por Burmeister (1892), quien describió algunas "inscripciones y pinturas indígenas" (Burmeister, 1892, p. 236), incluyendo pinturas geométricas y grabados en el cañadón Yaten Guajen. Ochenta años más tarde, Molina $(1971,1972)$ publicó numerosas observaciones de arte rupestre dispersas en distintas porciones de la región, incluyendo pinturas geométricas y figurativas y grabados en los cañadones El Lechuza y Yaten Guajen. Molina también definió una secuencia estilística ${ }^{3}$ basada en criterios muy heterogéneos, usados de manera asistemática y dispar -motivos en un caso, técnicas en otro, formas de composición en otro, etc.-, lo cual hace que dicha secuencia estilística se encuentre actualmente en desuso.

Otras menciones al arte rupestre de esta región han sido realizadas por Gradin, quien indica la existencia de varios motivos pintados y grabados en los cañadones Yaten 
Guajen, Platero y Mercerá, incluyendo negativos de mano superpuestos a motivos grabados -sin especificar su tipo- (Gradin, 2000, pp. 69-70). El mismo autor menciona que MNRSC es una de las regiones de Patagonia donde la técnica de "grabado fino" ha sido identificada (lo cual coincide con las observaciones de Molina), incluyendo incisiones curvilíneas y rectilíneas formando grillas o reticulados, así como también "motivos geométricos ornamentales" (Gradin, 2001, p. 858). En clasificaciones estilísticas previas Gradin ya había atribuido los grabados de la Margen Norte del Río Santa Cruz a la Tendencia Abstracto-Representativa, que ubicó temporalmente post 2600 años AP (Gradin, 1988).

Trabajos más recientes, desarrollados por Franco y colegas, generaron información sobre ocupaciones humanas en la región desde ca. 7700 años AP (sitio Yaten Guajen 12, $7717 \pm 77$ AP; Franco, 2008, 2012), hasta momentos históricos recientes (ver Cirigliano, 2016). Así, las evidencias analizadas hasta el momento sugieren que el lapso comprendido entre ca. 1700 años AP (sitio Mercerat 1, $1640 \pm 20$ AP; Franco, Cirigliano, Fiore, Ocampo y Acevedo, 2014) y ca. 1100 años AP (sitio Bi Aike 3, 1155 \pm 40 AP; Franco, Cardillo y Otaola, 2007) fue el de mayor intensidad de ocupación (Franco et al., 2014). En términos generales, las bajas densidades y diversidad de los conjuntos líticos recuperados en superficie y en excavaciones (sitios Bi Aike 3, Mercerat 1, Yaten Guajen 1, 2, 4, 5 y 12), sumadas a la presencia de tecnología de hojas, fueron interpretadas como indicadores de situaciones de alta movilidad vinculadas con la realización de actividades específicas (de carácter efímero), que articulaban espacios próximos entre sí (dentro y fuera de los cañadones), con poca redundancia específica en el uso de sitios producto de la gran oferta de reparos disponibles (Cirigliano, 2016; Franco et al., 2014).

En el marco de estas investigaciones se planteó la posibilidad de que el arte rupestre de la Margen Norte del Río Santa Cruz haya sido producido -en su mayor parte- durante el lapso comprendido entre $c a .1700$ y 1100 años AP, cuando la señal de ocupación humana es más intensa en la región (Franco et al., 2014). Sin embargo, nunca se descartó la potencial existencia de eventos de producción rupestre anteriores a este momento. El principal indicador utilizado como base para la asignación temporal a momentos recientes de la secuencia regional consiste en la escasez de sitios en la región con dataciones por fuera de este lapso (Franco et al., 2014). En el caso de las pinturas, la presencia de pigmentos en capas arqueológicas correspondientes a este lapso se consideró como un indicador adicional (sitios Bi Ake 3, Mercerat 1 y Yaten Guajen 1; Franco et al., 2014). En el caso de los grabados, su asignación temporal se efectuó mediante comparaciones con tipos de motivos grabados similares a los de las mesetas basálticas del centro-oeste de la provincia de Santa Cruz, ya asignados a momentos tardíos (Acevedo et al., 2013; Fiore y Ocampo, 2009; Franco et al., 2014; Re, 2010). A su vez, en la región bajo estudio las relaciones entre grabados y pinturas respecto a si están superpuestos/subyacentes no son unívocas, razón por la cual no generan criterios diagnósticos para dataciones relativas (Franco et al., 2014). Un nuevo dato de relevancia para el tema ha sido aportado por la reciente publicación de un sello arqueológico en el sitio CG3 de la meseta del lago Guitarra (centro-oeste de la provincia de Santa Cruz), sobre motivos grabados similares a los que conforman el repertorio de la región bajo estudio -circunferencia con apéndice, línea sinuosa y tridígito-, con un fechado ante quem de ca. 1200 años AP (Re et al., 2016), el cual es consistente con la asignación temporal previamente realizada. Finalmente, la presencia de marcas de ganado y grafitis con letras y números arábigos constituyen evidencias de eventos de producción de imágenes rupestres posteriores al lapso mencionado, más relacionadas con momentos históricos recientes.

Las prospecciones y análisis desarrollados en el marco de estos trabajos previos han demostrado que el arte rupestre se distribuye a lo largo de varios kilómetros en algunos 
de estos cañadones: por ejemplo, en el cañadón Yaten Guajen, registros preliminares demostraron que se extiende por más de $10 \mathrm{~km}$ continuos (Fiore y Ocampo, 2009). Dada esta característica particular de la región, que implica la distribución de imágenes de manera consistente a lo largo de extensas porciones del soporte rocoso, su registro y análisis tuvo que ser adecuado a esta gran escala generada por la propia acción humana en el pasado. Así, se efectuaron inicialmente estudios sistemáticos de distintos sectores del cañadón (YGII, III, IV, V y VI), que permitieron evaluar los tipos de emplazamientos de las imágenes, la frecuencia de unidades topográficas con y sin arte, las clases y tipos de motivos que constituyen el repertorio de imágenes y la técnica general predominante en cada sector (Acevedo et al., 2012-2014). Posteriormente, se desarrolló un análisis cuantitativo más detallado acerca de numerosas variables que subyacen a la caracterización del trabajo de producción artística en tres sectores del cañadón (YGII, III y IV), incluyendo: $\mathrm{N}$ y porcentaje de topografías donde se emplazan las UT con arte, $\mathrm{N}$ máximo de paneles por UT, $\mathrm{N}$ y porcentaje de técnicas específicas empleadas en cada UT, $\mathrm{N}$ de tipos de motivos que nunca aparecen combinados, $\mathrm{N}$ máximo de combinaciones de tipos de motivos en una misma UT. También se desarrolló el cálculo de numerosos índices para la evaluación de la inversión laboral en: cantidad de motivos, variedad del repertorio, combinación de tipos de motivos, uso de técnicas específicas para producir determinados tipos de motivos y asociación de técnicas generales con tipos de topografías donde se emplazaron las imágenes (Fiore y Acevedo, 2016). En este trabajo se retoman resultados del anterior (ver Tablas 1 y 2) con el objeto de contextualizar la nueva información, orientada a profundizar la evaluación de las pautas de construcción de paisajes rupestres identificables a partir del análisis de la caracterización de las imágenes observadas y registradas a escalas espaciales amplias. Es necesario destacar que no se trata de muchos sitios discretos con arte rupestre sino de un continuum de paneles con imágenes que se extienden a lo largo de kilómetros de un mismo cañadón. La creación del paisaje rupestre está dada entonces, entre otros elementos, por la frecuencia, expansión y variedad/recurrencia de los motivos usados para marcar el espacio, por las técnicas elegidas para plasmar las imágenes en los soportes, que generan efectos específicos de contraste y textura entre imagen y roca, y por la elección de los tipos de topografías elegidas para emplazarlas. Tanto para producir como para visualizar este paisaje, es necesario movilizarse dentro de él: en dicha conjunción entre imagen, topografía y movimiento es que emerge la agencia humana del pasado, materializada en el paisaje rupestre conservado y perceptible en el presente. En tal sentido, hemos desarrollado una aproximación metodológica que nos ha permitido generar un primer panorama de la materialidad de las imágenes, su distribución y su variabilidad espacial.

\section{El registro del paisaje rupestre: una aproximación distribucional}

Habitualmente, el arte rupestre se halla emplazado en sitios arqueológicos con delimitaciones espaciales relativamente claras y discretas, definidas a partir de la presencia de motivos emplazados en el soporte rocoso. A ello se suma que en muchas ocasiones el arte rupestre se encuentra emplazado en cuevas, aleros o conjuntos de bloques, cuyas propias delimitaciones topográficas contribuyen a la delimitación empírica del "sitio". Sin embargo, existen algunos casos en los cuales la escala de "sitio" no es la más operativa, ya que la extensión de las imágenes ocurre a lo largo de paredones en largas formaciones rocosas como bardas, dando lugar a grandes extensiones de paneles con imágenes, cuya separación en "sitios" discretos resulta dificultosa. Tal es el caso del cañadón Yaten Guajen, ubicado en la porción norte del río Santa Cruz cuya orientación general corre en dirección Norte-Sur, desembocando en el mencionado río. En este cañadón hemos seleccionado dos sectores diferenciales del paisaje natural para iniciar relevamientos de arte rupestre y evaluar si las imágenes constituyen una continuidad paisajística o si, por el contrario, muestran características diferenciales. 


\begin{tabular}{|c|c|c|c|c|c|}
\hline \multicolumn{3}{|c|}{ YGII } & \multicolumn{3}{|c|}{ YGIV } \\
\hline UT\# & NM & NTM & UT\# & NM & NTM \\
\hline UTo1 & 2 & 1 & UTo1 & 4 & 1 \\
\hline UTo2 & 2 & 1 & UTo2 & 1 & 1 \\
\hline UTo3 & 9 & 4 & UTo3 & 27 & 11 \\
\hline UTo4 & 12 & 2 & UTo4 & 9 & 6 \\
\hline UTos & 52 & 3 & UTos & 2 & 2 \\
\hline UTo6 & 4 & 2 & UTo6 & 2 & 2 \\
\hline UTo7 & 3 & 2 & UTo7 & 14 & 8 \\
\hline UTo8 & 20 & 2 & UTo8 & 11 & 2 \\
\hline UTo9 & 3 & 2 & UTo9 & 11 & 4 \\
\hline UT10 & 5 & 1 & UT10 & 16 & 2 \\
\hline $\mathrm{UT}_{11}$ & 3 & 1 & - & - & - \\
\hline $\mathrm{UT}_{12}$ & 2 & 1 & - & - & - \\
\hline $\mathrm{UT}_{13}$ & 4 & 1 & - & - & - \\
\hline $\mathrm{UT}_{14}$ & 6 & 3 & - & - & - \\
\hline $\mathrm{UT}_{15}$ & 4 & 1 & - & - & - \\
\hline UT16 & 6 & 1 & - & - & - \\
\hline $\mathrm{UT}_{17}$ & 1 & 1 & - & - & - \\
\hline UT18 & 1 & 1 & - & - & - \\
\hline $\mathrm{UT}_{19}$ & 1 & 1 & - & - & - \\
\hline UT2O & 1 & 1 & - & - & - \\
\hline $\mathrm{UT}_{21}$ & 4 & 2 & - & - & - \\
\hline UT22 & 11 & 4 & - & - & - \\
\hline $\mathrm{UT}_{23}$ & 1 & 1 & - & - & - \\
\hline UT24 & 13 & 3 & - & - & - \\
\hline $\mathrm{UT}_{25}$ & 4 & 2 & - & - & - \\
\hline UT26 & 32 & 2 & - & - & - \\
\hline Total & 206 & 14 & Total & 97 & 23 \\
\hline
\end{tabular}

Tabla 1. N de Motivos (NM) y N de Tipos de Motivos (NTM) presentes en cada UT (unidad topográfica) en YGll y YGIV. Nota: recordar que dado que los TM se repiten entre dos o más UT, el N total de TM (repertorio completo) no proviene de la sumatoria de TM presentes en cada UT.

Ambos sectores se hallan en una amplia curva que describe el cañadón, que quiebra la dirección general del cañadón y se orienta de manera Este-Oeste; en los dos casos se relevó la pared sur del cañadón ${ }^{4}$. El sector Yaten Guajen II (YGII) constituye una porción del cañadón netamente cerrada y encajonada, con ambas paredes rocosas paralelas y enfrentadas entre sí, con una alta inter-visibilidad entre paredes debido a su relativamente corta distancia (60 a $100 \mathrm{~m}$ aproximadamente), pero baja visibilidad desde cada pared ya que no habilita la observación hacia otros sectores del entorno debido a su estrecha angostura (Figura 2) (sensu Gradin, 2000). El sector Yaten Guajen IV (YGIV), contiguo al anterior, es claramente abierto debido a que la pared norte se aleja de la pared sur, formando la pared norte una apertura semicircular similar a un anfiteatro, que se enfrenta a la pared sur de manera mucho más alejada $(1.000 \mathrm{~m}$ aproximadamente), con baja inter-visibilidad entre paredes, pero alta visibilidad desde cada pared, permitiendo un amplio dominio visual del entorno (Figura 3).

En estos casos, dadas las propias características de la extensión del paisaje rupestre, es más adecuado producir un panorama distribucional que permita efectuar una

4. Cabe señalar que en el caso de YGll se observó la presencia de arte rupestre en la pared norte del cañadón, que no fue procesado en este trabajo con el objeto de mantener coherencia metodológica y la continuidad de muestreo con YGIV. 


\begin{tabular}{|c|c|c|c|c|}
\hline \multirow{2}{*}{ Repertorio de TM } & \multicolumn{2}{|c|}{ YGII } & \multicolumn{2}{|c|}{ YGIV } \\
\hline & Frecuencia & Distribución & Frecuencia & Distribución \\
\hline Antropomorfo* & 3 & 1 UT & 1 & 1 UT \\
\hline Circulo & - & - & - & - \\
\hline Circunferencia & 49 & 5 UT & 20 & $6 \mathrm{UT}$ \\
\hline Circunferencia + línea & 1 & 1 UT & 2 & 1 UT \\
\hline Circunferencia + tridígito & - & - & 1 & 1 UT \\
\hline $\begin{array}{l}\text { Conjunto irregular de segmentos } \\
\text { adosados }\end{array}$ & - & - & 1 & 1 UT \\
\hline Cruz & - & - & 1 & 1 UT \\
\hline Grafiti $=$ marca ganado & 2 & 1 UT & 5 & 2 UT \\
\hline Grilla-reticulado & - & - & 1 & 1 UT \\
\hline Línea curva & 3 & 1 UT & 5 & 1 UT \\
\hline Línea puntos & - & - & 9 & 2 UT \\
\hline Línea recta & 79 & 5 UT & 10 & 2 UT \\
\hline Línea sinuosa & - & - & 1 & 1 UT \\
\hline Línea U & - & - & 3 & 1 UT \\
\hline Línea U + otros elementos & - & - & 2 & 2 UT \\
\hline Manchas & 8 & 4 UT & - & - \\
\hline Mano negativa & 43 & 18 UT & 1 & 1 UT \\
\hline Mano positiva & 3 & 3 UT & 1 & 1 UT \\
\hline Meandro & - & - & 2 & 2 UT \\
\hline Óvalo & 3 & 1 UT & 1 & 1 UT \\
\hline Óvalo + línea & - & - & 2 & 1 UT \\
\hline Piqueteado disperso & 5 & 2 UT & 16 & 6 UT \\
\hline Puntos & 4 & 2 UT & 5 & 1 UT \\
\hline Puntos + línea & 1 & 1 UT & - & - \\
\hline Tridígito & 2 & 1 UT & 7 & 3 UT \\
\hline NTM = repertorio por transecta & $14 \mathrm{TM}$ & - & $23 \mathrm{TM}$ & - \\
\hline $\mathrm{N}$ motivos por transecta & 206 & - & 97 & - \\
\hline $\begin{array}{l}\text { NTM compartidos = repertorio en } \\
\text { común entre transectas }\end{array}$ & $12 \mathrm{TM}$ & - & $12 \mathrm{TM}$ & - \\
\hline UT con AR & 26 & - & 10 & - \\
\hline UT $\sin A R$ & 25 & - & 48 & - \\
\hline Tasa N TM / N UT AR & 0,5 & - & 2,3 & - \\
\hline TM de mayor distribución por UT & - & $\begin{array}{l}\text { mano negativa } \\
(\mathrm{n}=18 \mathrm{UT})\end{array}$ & - & $\begin{array}{c}\text { circunferencia } \\
(n=6 \text { UT }) \\
\text { piqueteado disperso } \\
(n=6 \text { UT })\end{array}$ \\
\hline Tasa NM / extensión transecta & 0,40 & - & 0,11 & - \\
\hline Tasa NM / N UT AR & 7,92 & - & 9,70 & - \\
\hline
\end{tabular}

Tabla 2. Frecuencia y distribución de TM (tipos de motivo) en YGll y YGIV.

aproximación exploratoria a las principales características de dicho paisaje. Con este propósito, luego de realizar prospecciones iniciales en MNRSC y de observar la importante extensión de las imágenes rupestres a lo largo de los cañadones (Fiore y Ocampo, 2009), decidimos desarrollar un método de registro distribucional que 


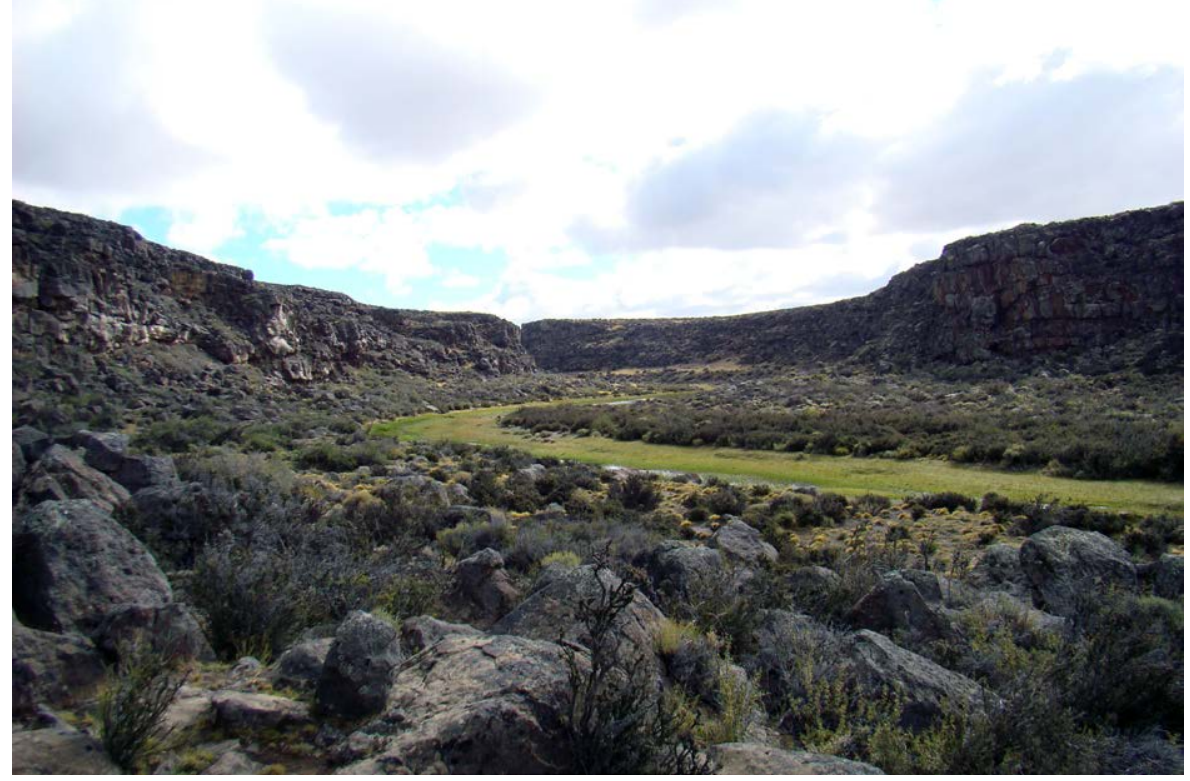

Figura 2. Ejemplo de visibilidad del entorno desde YGII.

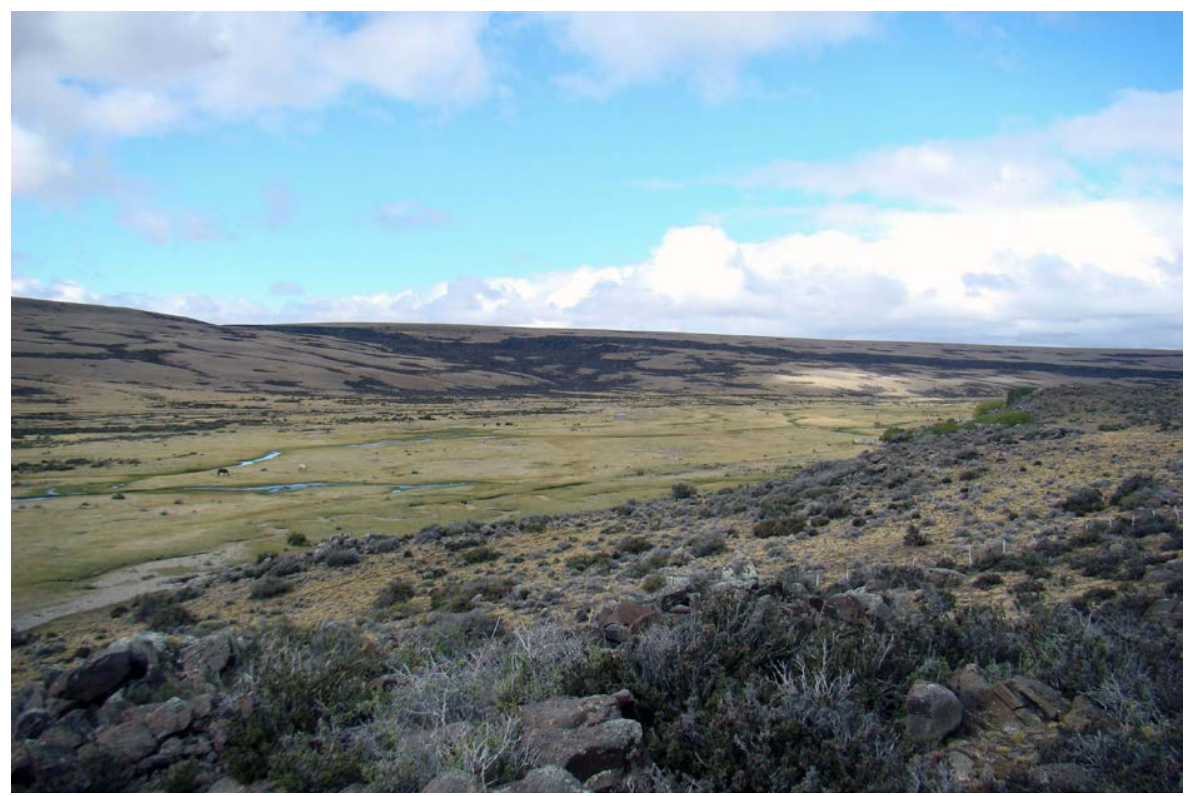

Figura 3. Ejemplo de visibilidad del entorno desde YGIV.

implica el muestreo de arte rupestre en tres escalas espaciales inclusivas: la transecta, las unidades topográficas (UT) y los motivos.

En este método, la transecta se define como una porción del soporte rocoso de una extensión limitada, la cual es inspeccionada a intervalos iguales para buscar, identificar y registrar la presencia/ausencia de UTs con arte rupestre. La extensión de la transecta y el tamaño de los intervalos iguales se definen de acuerdo a los objetivos de investigación, estrategias de muestreo, características del arte rupestre (visibilidad, extensión, densidad, estado de conservación, etc.) y condiciones del trabajo de campo (accesibilidad, movilidad, etc.). Idealmente, para facilitar las comparaciones, las transectas deberían ser de la misma extensión (e.g. $1.000 \mathrm{~m}$ ) y con intervalos del mismo tamaño (e.g. cada $15 \mathrm{~m}$ ); sin embargo, 
dadas las limitaciones arriba mencionadas, esto no siempre es posible. En tales casos, si la extensión de transecta o los intervalos son distintos, las comparaciones son igualmente posibles pero requieren evaluar los datos para asegurarse de que los mismos no sean dependientes de los tamaños de las muestras (ver más abajo).

Las UT (unidades topográficas) se definen operativamente como porciones del soporte limitadas por rasgos naturales (grietas, fisuras, cambios de plano cóncavo/convexo, cambios de ángulo vertical/horizontal, cambios de orientación cardinal, etc.) que se presentan a lo largo de las paredes de bardas o cañadones como superficies disponibles sobre las cuales es posible producir arte rupestre. Algunas de estas porciones del soporte han sido efectivamente utilizadas para emplazar imágenes rupestres, mientras que otras no tienen imágenes visibles actualmente (sea porque nunca han sido producidas, sea porque su deterioro ha sido total y actualmente no hay rastros visibles de las imágenes). En los casos en que las UT tienen imágenes rupestres, la extensión de las propias imágenes colabora a la definición de la UT, por lo cual nunca se define una UT segmentando una composición visual rupestre, sino que en su registro de campo siempre se respeta la totalidad del panel o paneles que contienen motivos dentro de la UT. Las UT pueden estar conformadas por uno o varios paneles (denominados UT-p). Definimos como panel a la concentración espacial de dos o más motivos cuya proximidad permite relacionarlos visualmente entre sí como formando parte de una composición plástica -producida sincrónica o diacrónicamente- $y$ segregarlos de otro/s motivos alejados de aquellos, que conforman otro/s paneles.

Finalmente, los motivos se definen operativamente como unidades discretas de diseño, constituidos por uno o varios elementos que forman una unidad visual y material, y que están separados visual y materialmente de otros motivos (Aschero y Martel, 20032005; Gradin, 1978; Loendorf, 2001).

Durante el trabajo de campo se define inicialmente la extensión de la transecta y el tamaño de los intervalos, para luego registrar en una ficha de relevamiento las siguientes variables de acuerdo a cada escala espacial:

A) a escala de transecta:

» A1) coordenadas de Lat/Long al inicio y finalización de transecta;

» A2) tipo de soporte rocoso (e.g. basalto, ignimbrita, etc.);

» A3) presencia/ausencia de arte rupestre a intervalos regulares: esto genera un conteo total de UTs con y sin arte;

» B) a escala de UT, en aquellas UTs que tienen arte rupestre:

» B1) coordenadas Lat/Long de la UT;

» B2) tipo de morfología de la topografía del soporte rocoso en la que se emplaza el arte (e.g. cueva, alero, paredón, bloque);

» B3) orientación cardinal de la UT;

» B4) estado de conservación del arte en la UT;

») a escala de motivo;

" C1) tipo de motivo (TM): cada tipo se define de acuerdo a una serie de atributos morfológicos recurrentes que permiten la clasificación de varios motivos reales dentro 
de una misma categoría de tipo (e.g. mano negativa), la cual es morfológicamente diferente de otras categorías;

》 C4) pátina
pintados).

Los contenidos de la ficha de relevamiento se vuelcan a una base de datos relacional de dos escalas: una hoja de datos por UT y otra hoja de datos por motivos. Estas dos hojas de datos se relacionan entre sí por el número de UT, y mantienen un vínculo de uno-a-varios, dado que una misma UT puede contener uno, dos o más motivos.

El panorama resultante de la aplicación del método distribucional de registro de arte está focalizado en caracterizar a los paisajes rupestres de acuerdo con la frecuencia, proporción, densidad, expansión y variedad de los motivos y tipos de motivos, así como en hallar patrones relacionados con el emplazamiento de tipos de motivos, su combinación en composiciones de paneles, su vínculo con las técnicas de producción usados para producirlos y con los rasgos topográficos de su emplazamiento. La utilidad principal de este método reside en su aplicación sobre escalas espaciales amplias, permitiendo caracterizar paisajes rupestres que, de ser registrados por el método convencional, segmentarían a los paneles conformando arbitrariamente "sitios" pero consecuentemente no darían cuenta del continuum visual generado por la extensión de las imágenes en el espacio de los cañadones. Las limitaciones de este método incluyen: a) que no está diseñado para dar cuenta de información estilística; b) que estudia a todas las imágenes juntas como un fenómeno aditivo, dejando el factor temporal como constante; sin embargo, la evaluación de las pátinas y superposiciones puede posteriormente dar cuenta de algunas discriminaciones diacrónicas, las cuales no son abarcadas en detalle en este trabajo.

\section{Resultados obtenidos: la cuantificación de datos para la cualificación de los paisajes rupestres}

En este trabajo presentamos la comparación entre dos transectas efectuadas en el curso medio del cañadón Yaten Guajen, en los dos sectores arriba mencionados: Yaten Guajen II (YGII) y Yaten Guajen IV (YGIV). YGII es una transecta de $510 \mathrm{~m}$ de largo; YGIV es una transecta de $870 \mathrm{~m}^{6}$; la primera termina a $26 \mathrm{~m}$ de distancia del inicio de la segunda (Figura 1).

\section{Patrones cuantitativos univariados a escala de UT}

El porcentaje de UTs con arte en cada transecta es un indicador relevante para iniciar la evaluación de la intensidad de uso del espacio del soporte rocoso. En los casos bajo estudio, YGII, que es la transecta más corta, tiene $51 \%$ de UTs con arte rupestre, mientras que YGIV, que es la transecta más larga, tiene $17 \%$ de UTs con arte. Más aún, la frecuencia de UTs con arte en cada caso es estadísticamente significativa $\left(\mathrm{X}^{2}=16,50\right.$; $\mathrm{df}=1 ;$ Pval $=0,0000 ; 99 \%$ confianza). Esto implica que en YGII hubo más UTs usadas para emplazar arte que si la distribución fuera azarosa, lo cual señala que la intensidad de producción de arte rupestre en términos de densidad fue mayor en YGII que en YGIV sin que ello dependa del tamaño de las muestras (Tabla 1).

En cuanto al $\mathrm{N}$ y \% de tipos de morfología de la topografía (ej. cueva, paredón, etc.) utilizados para emplazar motivos, YGII tiene $84 \%(n=22)$ de sus UTs con arte
5. Las técnicas artísticas incluyen: a) técnicas de producción (todas las formas de grabado, pintura y sus combinaciones), b) técnicas gráficas, b1) tratamiento grafico de la morfología del motivo (lineal, perimetral, areal) y b2) modo de aplicación del trazo (continuo, discontinuo).
6. Debido a que estas dos transectas fueron efectuadas en momentos iniciales del proyecto de investigación en curso, YGll fue relevada a intervalos iguales de 10 $\mathrm{m}$ al tiempo que YGIV fue relevada a intervalos iguales de $15 \mathrm{~m}$ para explorar las potencialidades de registro de cada intervalo, las cuales resultaron similares. Sin embargo, dadas las diferencias de tamaño e intervalos entre ambas transectas, para que sus comparaciones sean válidas es necesario evaluar sus resultados analizando potenciales sesgos debidos a los tamaños de las muestras. En este sentido, el cálculo de la tasa transecta/ intervalo demuestra que ambas son comparables, ya que YGII tiene un índice de 51 y YGIV de 52. Esto se debe a que la menor extensión de YGll es compensada por sus intervalos más cortos (que implican más puntos de recolección de datos), mientras que la extensión mayor de YGIV es compensada por sus intervalos más largos (que implican menos puntos de recolección de datos): esto hace que sus tasas transecta/ intervalo sean similares. 
Técnicas generales por UT en YGII y YGIV

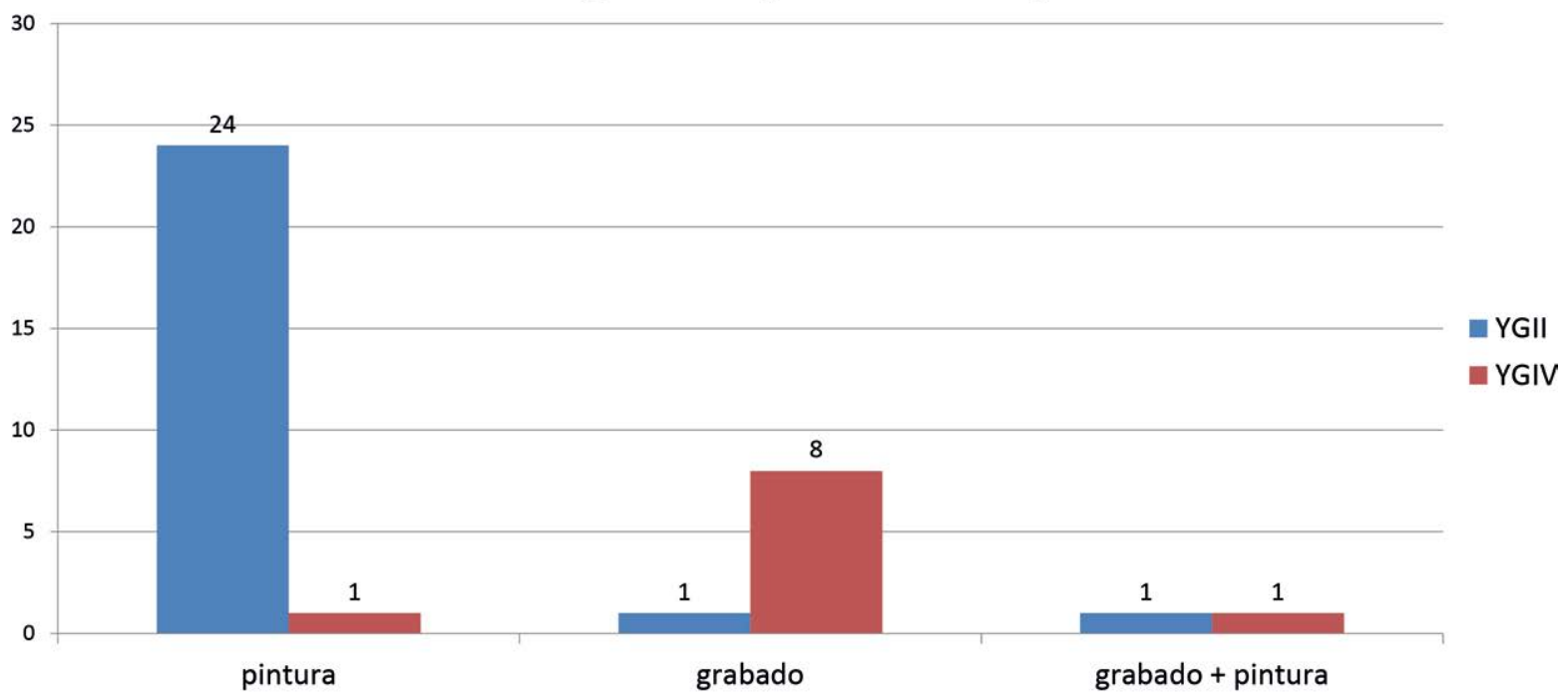

Figura 4. $N$ de Técnicas en YGll y YGIV.

7. Es crucial recordar que esta transecta tiene un total de 10 UTs con arte, lo cual implica que cualquier cambio menor en la muestra podría alterar significativamente estos porcentajes. emplazadas en aleros, mientras que YGIV tiene 50\% $(n=5)$ de sus UTs con arte emplazadas en paredones y $40 \%(n=4)$ en aleros ${ }^{7}$. También, YGII tiene tres UTs $(11 \%)$ en cuevas y ninguna en bloques, mientras que YGIV no tiene ninguna en cuevas y solo una (10\%) en bloques. Estos datos sugieren interesantes tendencias respecto del uso de la topografía en cada porción del cañadón: YGII tiene un mayor uso de aleros que YGIV; YGIV tiene un mayor uso de paredones que YGII; y ambas localidades muestran un uso bajo o nulo de cuevas y bloques. El hecho de que aleros y paredones sean los tipos de morfología de la topografía más frecuentemente usados para la producción del arte rupestre no puede ser atribuido directamente a una elección antrópica, dado que hay muy pocas cuevas en el curso medio de este cañadón; sin embargo, esto implica que estas imágenes estaban destinadas a ser vistas desde puntos relativamente distantes, pero desde dentro del cañadón. También, el hecho de que pocos o ningún bloque muestren actualmente arte rupestre indica que: a) si estos estaban previamente formando parte de los paredones o aleros, han habido pocos desprendimientos luego de la producción de las imágenes; b) si estos fueron decorados luego de su desprendimiento, no han sido elegidos frecuentemente como soportes, posiblemente por su menor visibilidad.

En cuanto a las técnicas generales con las cuales se produjeron las imágenes, en YGII predominan las UT con pinturas ( $92 \%$ de las UT) y en YGIV predominan las UT con grabados ( $80 \%$ de UT) (Figura 4$)$.

Esto a su vez puede ser relacionado con los tipos de morfología de la topografía donde se han emplazado las imágenes. La mayor frecuencia de uso de aleros en YGII (84\%) contrasta con el uso más parejo de aleros y paredones en YGIV (40\% y 50\% respectivamente), lo cual puede vincularse con la relativa protección ofrecida por cada tipo de topografía a las imágenes allí emplazadas: los aleros proveen mayor reparo que los paredones, por lo tanto - en un mismo tipo de roca soporte- las pinturas tendrán mayor posibilidad de conservación diferencial en los primeros que en los segundos, mientras que los grabados tendrán comparativamente menos riesgo de deterioro que las pinturas (Bednarik, 2001; Fiore, 2006; Rosenfeld, 1988). En tal sentido, en YGII, donde los aleros son usados más frecuentemente, predominan las pinturas, mientras que en YGIV, donde aleros y paredones han sido usados de manera más pareja, predominan los grabados, que pueden soportar comparativamente una exposición mayor a los factores ambientales. 
Respecto de los tipos de técnicas de producción empleadas en cada transecta, en YGII la más frecuente es la pintura negativa $(n=12 \mathrm{UTs}, 46 \%)$, seguida por la pintura positiva $(\mathrm{n}=6 \mathrm{UTs}, 23 \%)$ y por la combinación de ambas en la misma UT ( $\mathrm{n}=6 \mathrm{UTs}, 23 \%$; Tabla 1). Contrariamente, YGIV muestra una preferencia por el piqueteado ( $n=6 \mathrm{UT}, 60 \%)$, seguida por casos de combinaciones de piqueteado y/o incisión con otras técnicas de grabado (salvo una sola UT). Esto es particularmente relevante en la caracterización de la marcación visual de cada sector del cañadón, dado que la materialidad de las imágenes es un aspecto crucial de su apariencia visual: el predominio de un grupo de técnicas (pintura versus grabado) y la escasa combinación de ambos en una misma UT marca un rasgo central del paisaje visual creado por el arte rupestre en Yaten Guajen. Las técnicas de pintura son aditivas y generan imágenes coloreadas, mientras que las técnicas de grabado son sustractivas y generan coloración por contraste con el soporte rocoso, pero generan también texturas más evidentemente perceptibles (rugosas, con hoyuelos, etc.). Tomando esto en cuenta, en YGII el predominio de imágenes pintadas -aditivas y coloreadas- contrasta con el predominio de imágenes grabadas -sustraídas y texturizadas- en YGIV. Por lo tanto, estas cuantificaciones permiten analizar la distribución y predominancia de las técnicas rupestres a lo largo del espacio, proveyendo una forma de caracterizar los paisajes rupestres creados por los rasgos visuales de cada técnica.

Finalmente, respecto del número y porcentaje de UTs en las cuales se han ejecutado superposiciones de motivos, esta información contribuye a evaluar cuántas veces se empleó este recurso compositivo, lo cual a su vez aporta información acerca de la intensidad de re-utilización de un mismo panel. En YGII tres UTs (11\%) tienen superposiciones de motivos mientras que en YGIV dos UTs (20\%) presentan superposiciones. Ello arroja un panorama muy similar entre ambas localidades, mostrando que las superposiciones fueron infrecuentes en ambos casos.

Las formas en que las imágenes se distribuyen a lo largo de las UTs para así construir paisajes rupestres pueden evaluarse también analizando el $\mathrm{N}$ y \% de UTs con un solo motivo versus aquellas con varios motivos: la presencia de una alta proporción de UTs con motivos únicos indica una preferencia por su aislamiento, mientras que una alta proporción de UTs con varios motivos implica una preferencia combinarlos en un mismo espacio del soporte. En YGII se registran 13 UTs con motivos únicos (50\%) y 13 UTs con varios -dos o más- motivos (50\%) (Figura 5); en YGIV hay dos UT con motivos únicos (10\%) y ocho UTs con varios motivos (90\%) (Figura 5). Esto marca un claro contraste entre ambas localidades: YGII muestra una proporción muy balanceada de UTs con motivos únicos y con varios motivos, mientras que YGIV muestra una tendencia más marcada hacia emplazar varios motivos en una misma UT.

Respecto de los TM (tipos de motivos) elegidos para ser emplazados como motivos únicos, ambas localidades muestran tendencias distintas: en YGII, de las 13 UTs con TMs únicos, 11 casos son negativos de manos; en YGIV, las dos UT con TMs únicos incluyen circunferencias (un TM muy frecuente en la región) y una línea en forma de U con segmentos adosados (un TM infrecuente en la región). A diferencia de YGII, el único negativo de mano en YGIV no ha sido emplazado de manera aislada, sino combinado con otros motivos. Así, YGII muestra una tendencia hacia la selección de un TM específico para ser emplazado de manera aislada, mientras que dicha tendencia no es verificable en YGIV (Tabla 2).

Complementariamente con lo anterior, es interesante también evaluar el $\mathrm{N}$ y \% de UTs con un TM (tipo de motivo) versus varios TMs: este dato ayuda a evaluar la variabilidad subyacente a cada transecta, dado que una alta proporción de UTs con varios TMs distintos implica variabilidad alta, y viceversa. A su vez, una alta variabilidad en la combinación de distintos TMs en una misma UT sugiere un cierto grado de libertad 
YGII y YGIV: cantidades de TM por UT

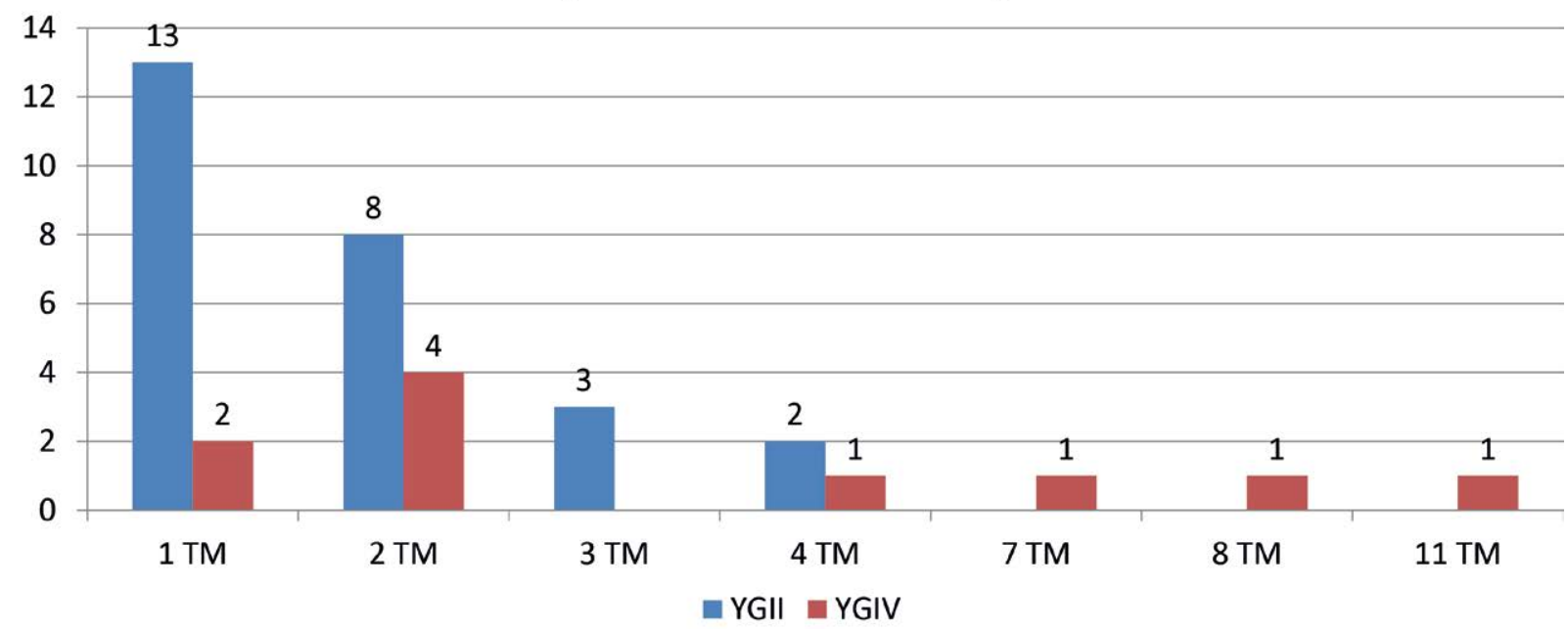

Figura 5. N de Tipos de Motivo por UT en YGll y YGIV.

creativa, sea en la producción sincrónica o en la acumulación sucesiva de TMs, mientras que la menor variabilidad de combinaciones de TMs implica un potencial mayor control social en las reglas de composición de las imágenes, ya que si hay mayor recurrencia en las combinaciones de TMs esto implica la existencia de convenciones subyacentes a la producción rupestre y un menor grado de libertad de creación, y viceversa.

En YGII, 13 UTs registran actualmente un solo TM (50\%) y 13 UTs registran varios -dos o más- TMs (50\%), mientras que en YGIV dos UTs registran un TM (20\%) y ocho UTs registran varios TMs (80\%). Esto muestra una preferencia por la creación de composiciones visuales con varios TMs en YGIV (que implica más lugar para la libertad creativa y reglas de composición acumulativas comparativamente menos estrictas), mientras que YGII muestra una proporción más equilibrada de elecciones compositivas con un TM y con varios TMs. La razón de estas diferencias podría en parte vincularse con los tipos de motivos elegidos para ser combinados (ver más abajo).

Una manera más detallada de cuantificar la información acerca de las combinaciones de TMs es analizar el número de TMs que han sido combinados en cada UT: esto provee información acerca del grado de variabilidad $u$ homogeneidad compositiva dominante en cada transecta. En YGII, que posee un repertorio total de 14 TM, se han combinado uno, dos, tres y hasta cuatro TMs en una misma UT, predominando:

a) 13 UTs con un TM (50\% de las UT de la transecta);

b) ocho UTs con dos TM (ver Figura 5).

En YGIV, que posee un repertorio total de 23 TM, se han combinado desde uno hasta 11 TM en una misma UT, predominando:

a) cuatro UTs con dos TM (40\% de las UT de la transecta);

b) el resto de las combinaciones son muy infrecuentes (ver Figura 6). Así, se infiere una relativa coincidencia entre YGII y YGIV: a pesar de sus distintos tamaños de repertorio ( $\mathrm{n}=14$ TM versus $\mathrm{n}=23$ TM respectivamente), ambas localidades tienden a caracterizarse por la combinación de pocos TMs en una misma UT. Esto implica que la composición plástica de cada UT ha sido generalmente 

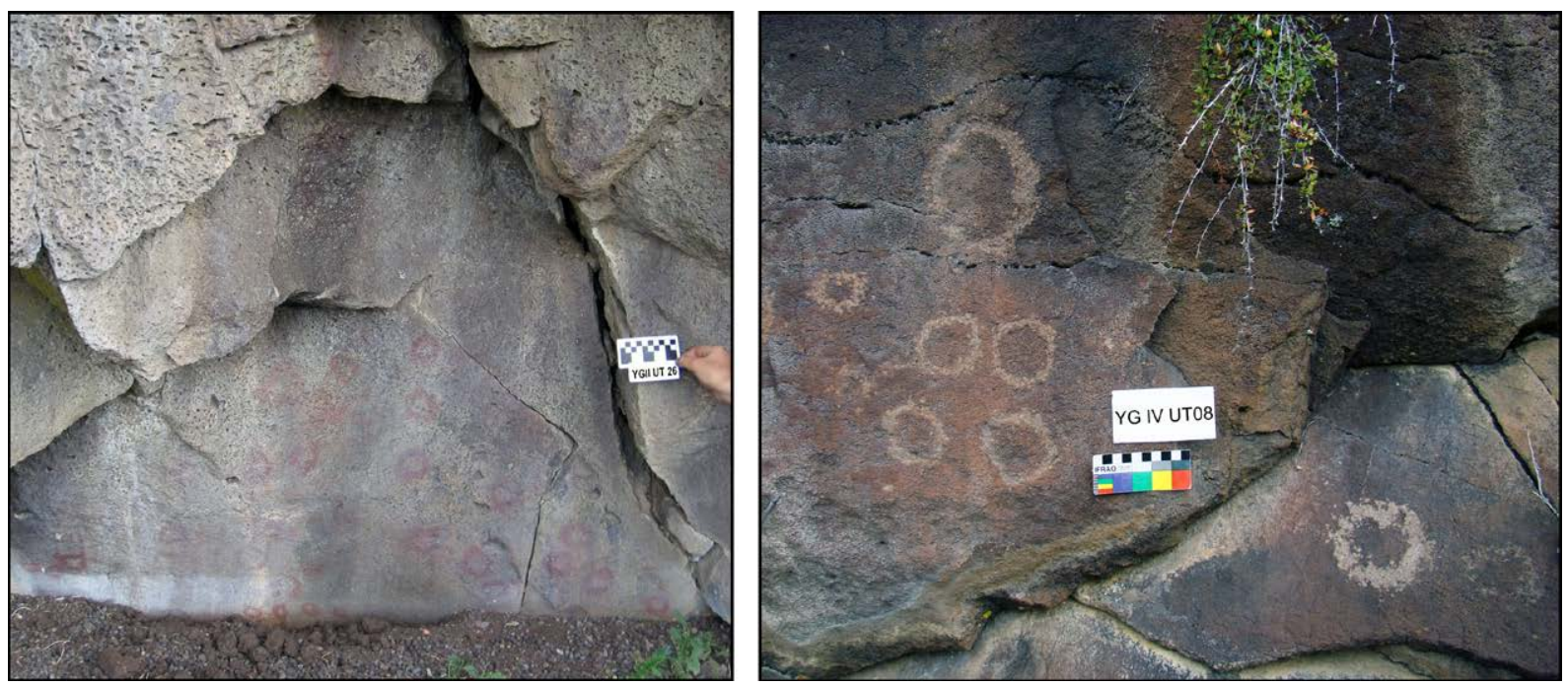

Figura 6. Circunferencias pintadas del YGII (izquierda) y circunferencias grabadas de YGIV (derecha).

más bien homogénea y de baja variabilidad intra-UT. Dicha homogeneidad es perceptible al pararse frente a cada UT y observarla individualmente; mientras que la heterogeneidad visual de cada sector es notoria solamente al caminar de una UT a la siguiente. Así, los paisajes rupestres del cañadón son apreciables en su real complejidad no solo mediante la percepción visual sino necesariamente acompañando a esta mediante el movimiento corporal.

\section{Patrones cuantitativos bivariados a escala de UT}

Las variables cuantificadas individualmente más arriba pueden ser interrelacionadas con el objeto de buscar posibles tendencias bivariadas por UT. En este trabajo nos centraremos en dos cruces de variables. Primero, respecto de los TM por tipo de topografía (contabilizados por presencia/ausencia en la UT), resulta notorio que las UT con manos negativas tienden a estar localizadas en aleros (19 UTs en YGII, una UT en YGIV), con pocos casos en cuevas (cuatro UTs en cuevas en YGII y ninguna en YGIV), mientras que en ambas transectas no hay casos registrados en paredones. Un TM que se comporta de manera distinta a la anterior son las circunferencias, ya que en YGII éstas están concentradas en los abrigos (cinco UTs) mientras que en YGIV están localizadas en paredones (cinco UTs) y en abrigos (dos UTs). Esto puede estar parcialmente relacionado con las técnicas de ejecución de imágenes en cada localidad: en YGII, donde predomina el uso de técnicas de pintura, las circunferencias fueron pintadas y emplazadas en abrigos (Figura 6), bajo condiciones de reparo ofrecidas que favorecen su preservación; mientras que en YGIV, donde predomina el uso del grabado, las circunferencias fueron piqueteadas y emplazadas principalmente en paredones (Figura 6), siendo que el grabado puede perdurar incluso en estos espacios abiertos y sin protección.

En segundo lugar, respecto de los usos de técnicas por tipo de topografía, se encuentran dos tendencias contrastantes. En ambas localidades, las imágenes producidas por pintura positiva y negativa se hallan mayormente en abrigos, y en menor frecuencia en cuevas (YGII), lo cual es esperable en términos de la protección relativa ofrecida por estas topografías a las imágenes pintadas; a pesar de ello en YGIV también hay casos de imágenes pintadas sobre bloques, que ofrecen un bajo potencial de preservación para éstas. A su vez, resulta interesante observar que todas las imágenes piqueteadas de YGII y la mayoría de las imágenes piqueteadas de YGIV están concentradas en aleros, 
mientras que solo una baja frecuencia de éstas se halla en paredones en YGIV. De este modo, mientras que la concentración primordial de imágenes pintadas en aleros puede ser parcialmente atribuible a condiciones de conservación, lo contrario no se sostiene para los grabados piqueteados, que aparecen registrados predominantemente en aleros pese a que podrían haber perdurado en los paredones. Ello sugiere la existencia de una elección efectuada por los creadores del arte rupestre de grabar imágenes en aleros, que no habría aprovechado abiertamente de sus posibilidades intrínsecas de conservación en espacios abiertos en términos de costo-beneficio, sino que habría privilegiado el tipo de topografía semi-protegida para emplazar allí los motivos piqueteados.

\section{Cuantificación de tendencias a la escala de motivo}

\section{Tendencias univariadas a escala de motivo}

A escala de motivo, el primer conteo básico a efectuar es el $\mathbf{N}$ de motivos (NM): en YGII se ha registrado un NM de 206, mientras que en YGIV se ha registrado un NM de 97 (Tabla 2). A primera vista, esto sugiere que la inversión laboral acumulada en cada transecta en términos de producción neta de NM habría sido mayor en YGII que en YGIV. Sin embargo estos datos deben sopesarse de acuerdo a las distintas extensiones de las transectas, con el objeto de evaluar los efectos potenciales del tamaño de la muestra sobre la cuantificación de NM. Los resultados son interesantes, dado que YGII, que es la transecta más corta (510 m), tiene un NM mayor, mientras que YGIV, que es la transecta más larga $(870 \mathrm{~m})$, tiene un NM menor. De hecho, el índice NM/ extensión de transecta es mayor en YGII $(0,40)$ y menor en YGIV $(0,11)$ (Tabla 2), lo cual parece confirmar esta tendencia. Podría sugerirse que esta tendencia general está potencialmente sesgada por el tamaño de intervalo de registro de UTs en cada transecta arriba mencionado (10 m para YGII y $15 \mathrm{~m}$ para YGIV); sin embargo, el índice NM/ NUT con arte -que responde a la pregunta sobre cómo se reparten en promedio los motivos respecto de las unidades topográficas que los contienen- es menor en YGII $(7,92)$ y mayor en YG IV $(9,70$; Tabla 2$)$, sugiriendo que dicho sesgo, de existir, no habría sido muy marcado.

La inversión laboral también puede evaluarse respecto de la variabilidad del repertorio rupestre registrado en cada transecta. En los casos bajo estudio, el $\mathbf{N}$ de tipos de motivos (NTM) es de 12 para YGII y 23 para YGIV (Tabla 2), lo cual sugiere una mayor inversión laboral en la variabilidad de la segunda transecta. Para evaluar si estas diferencias en los NTM dependen del tamaño de las transectas, calculamos primero el índice NTM/extensión de transecta, el cual es muy similar en ambas (YGII $=0,02$; YGIV =0,03; Tabla 2), sugiriendo que los rangos de los repertorios son proporcionales a los tamaños de las transectas, lo cual implicaría que ninguna de ellas tiene una marcada variabilidad respecto de la otra. En segundo lugar, calculamos el índice NTM/NUT con arte, cuyos resultados son 0,5 para YGII y 2,3 para YGIV (Tabla 2). Estos resultados emergen del hecho de que YGII tiene un menor repertorio distribuido en una mayor cantidad de UTs con arte, mientras que YGIV tiene un mayor repertorio concentrado en una menor cantidad de UTs con arte. Dicho contraste es además estadísticamente significativo $\left(\mathrm{X}^{2}=20,53 ; \mathrm{df}=3 ; \mathrm{Pval}=0,0001 ; 99 \%\right.$ confianza $)$ y reafirma que YGII tiene una menor variabilidad de repertorio que YGIV, independientemente del tamaño de las muestras. A su vez, estas diferencias de variabilidad de repertorio implican que en YGII la producción rupestre habría sido socialmente más "restrictiva" que en YGIV, donde habría sido comparativamente más "laxa" (generando o permitiendo mayor variabilidad de tipos de motivos). Las razones de la existencia de estas diferencias son sumamente difíciles de inferir y requieren de mayores análisis de los contextos arqueológicos asociados a ellas. Sin embargo, en términos de paisaje, es interesante notar que YGII, que se encuentra en una zona del cañadón más "encajonada" y cerrada y con menos apertura de visualización, es la transecta con más producción 

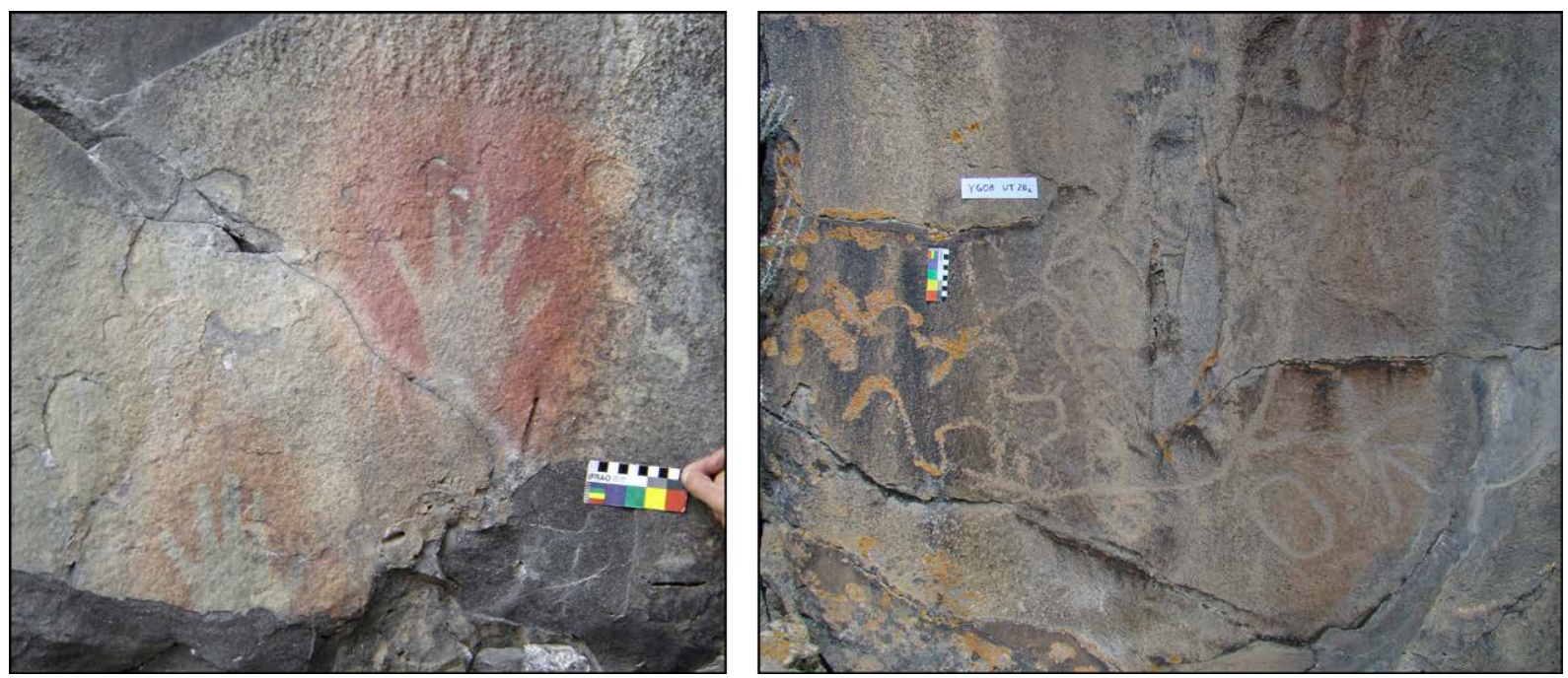

Figura 7. Motivos frecuentes en YGIl (izquierda) y YG IV (derecha).

de motivos $(n=206)$, menor repertorio $(\mathrm{NTM}=12)$ y alta frecuencia de tres TM en particular: circunferencias, líneas rectas y manos negativas. Contrariamente, YGIV, que se encuentra en una zona del cañadón más amplia y "abierta” y con mayor apertura de visualización, es la transecta con menor producción de motivos $(n=97)$, mayor repertorio $(\mathrm{NTM}=23)$ y frecuencias medias de tres motivos: circunferencias, piqueteados dispersos y líneas rectas, destacándose además la presencia de varios tipos de líneas -en frecuencias menores- y la cuasi-ausencia de manos. Por lo tanto, el paisaje rupestre de YGII aparece dominado por algunos motivos geométricos y por manos negativas (Figura 7), todos ellos pintados dentro de dicho escenario "encajonado". Contrariamente, el paisaje rupestre de YGIV, desarrollado en un escenario "abierto", aparece dominado por diversos motivos geométricos grabados (Figura 7), mientras que se registra solo un caso de mano negativa y otro de mano positiva pintadas, lo cual genera una marcada diferencia de este paisaje con el anterior.

Una caracterización más detallada de estos paisajes puede desarrollarse utilizando otros indicadores complementarios. Uno de ellos es el $\mathbf{N}$ de TM compartidos: cuanto mayor sea este número, puede inferirse una mayor proximidad en las reglas de producción de arte rupestre de cada sector del cañadón. En el caso bajo estudio, del repertorio de 14 TM de YGII y 23 TM de YGIV, el NTM compartido es de 12, incluyendo: circunferencias, líneas rectas, manos negativas, manos positivas, piqueteado disperso, tridígitos, etc. (Tabla 2). La cuantificación de estos $12 \mathrm{TM}$ compartidos muestra que abarcan una alta proporción del total de la producción rupestre acumulada en cada sector: $95,6 \%$ del total de motivos de YGII y 76,3\% del total de motivos de YGIV. Esto sugiere que, en términos de TMs compartidos, los dos sectores del cañadón mantuvieron relaciones fuertes y fluidas, dado que casi todo el repertorio de YGII está presente en YGIV, en altas proporciones. Esto es esperable, dado que se trata de sectores contiguos. Sin embargo, las formas en que estos repertorios fueron construidos y utilizados muestran diferencias entre transectas. En primer lugar, los motivos de YGII son mayormente pintados, mientras que los de YGIV son mayormente grabados. Esto marca una profunda diferencia material y visual que es insoslayable en la percepción de los respectivos paisajes de cada transecta.

Cabe evaluar también los TM más frecuentes de cada transecta, para analizar si son también los TM más expandidos en distintas $\mathrm{UTs}^{8}$, o si por el contrario existió alguna preferencia por concentrarlos en pocas UTs de la transecta (Tabla 2 y Figuras 5 y 6 ). Esta comparación permite destacar interesantes diferencias y similitudes en los paisajes

8. El conteo de TM por UT se efectúa contabilizando la presencia de un determinado TM en las UT y paneles de la transecta, sin importar si se registra uno o varios motivos de dicho tipo en cada UTp. Dado que el conteo se efectúa individualmente para cada TM, sin importar si hay otros TM presentes en una misma UT-p, la sumatoria de UT-ps excederá el N real de UTps en la transecta. 
rupestres de cada sector del cañadón. En YGII el TM más frecuente son las líneas rectas $(n=79)$ pero se encuentran concentradas en cinco UT, mientras que en YGIV registran pocas líneas rectas $(n=10)$ en dos UT. En YGII se favoreció la producción y dispersión de manos negativas ( $n=43$, en 18 UT y 24 UT-p), mientras que en YGIV la producción de manos negativas se redujo a un solo ejemplar en una UT. En YGII también fue frecuente la producción de circunferencias $(n=49)$ pero concentradas en cinco UT- $p$, mientras que en YGIV dicha producción fue menor $(\mathrm{n}=20)$ pero se distribuyó a lo largo de nueve UT-p.

Las combinaciones de TM más frecuentes han sido registradas dentro de los paneles (UTp). La presencia recurrente de dos o más TMs dentro del mismo UT-p sugiere la existencia de una potencial regla de composición plástica de la imagen, que puede haber operado de manera sincrónica pero también de manera diacrónica, generando adiciones sucesivas de nuevos motivos a la imagen, en cuyo caso la regla en cuestión sería relevante solamente para los últimos momentos de ejecución de la imagen (Acevedo et al., 2012-2014; Acevedo et al., 2013; Aschero, 1997; Leroi-Gourhan, 1967). Es importante notar además que las reglas de composición de la imagen pueden incluir no solamente la prescripción y/o tolerancia a combinar dos TM en un mismo panel, sino también a la prescripción y/o intolerancia hacia no ubicar dos TM en un mismo panel -ambas son significativas en tanto reglas implícitas o hábitos que subyacerían a la práctica de producción artística. Dado que en nuestro caso de estudio no se han determinado aún diferencias significativas de pátinas y superposiciones que permitan discernir entre distintos momentos de ejecución del arte rupestre, tomaremos el estudio de las combinaciones de TM como un conjunto indistinto, similar a un palimpsesto de imágenes.

Compararemos aquí las combinaciones de algunos TM específicos: circunferencias, manos negativas, manos positivas y tridígitos, que han sido seleccionados por su presencia en ambas transectas, con el objeto de evaluar su comportamiento diferencial o similar en la construcción de los respectivos paisajes rupestres. Dado que YGII muestra un alto número de manos negativas, sería esperable que, si las combinaciones se dieran de manera aleatoria, éstas fueran combinadas con varios TM del repertorio, incluyendo aquellos que aparecen con bajas frecuencias (Figura 8). Este es el caso de:

» las manos positivas (registradas en tres UT-p), que aparecen combinadas con manos negativas en dos UT-p;

» los tridígitos (registrados en una UT-p), que aparecen combinados con manos negativas en dicha UT-p.

Sin embargo, hay también otras tendencias contrapuestas:

»las circunferencias ( $\mathrm{n}=49$ en cinco UT-p), nunca aparecen combinadas con las manos negativas pese a la gran distribución espacial de éstas (en 24 UT-p); esto señala la potencial existencia de una regla de exclusión o de no-combinación, de circunferencias con manos negativas, que no parece solo atribuible al tamaño de la muestra, dado el alto $\mathrm{N}$ de manos negativas que genera la expectativa de combinaciones arriba señalada;

» interesantemente, en todos los casos las circunferencias aparecen siempre combinadas con otros TM, lo cual sugiere que para sus productores estas eran proclives a formar parte de composiciones visuales más variables, las cuales, sin embargo, excluían a las manos negativas tal como se verifica en el punto anterior;

" las manos negativas, que tienen alta frecuencia y alta distribución $(\mathrm{n}=43$ en 24 UT-p), aparecen sin combinación con otros TM en 16 UT-p, lo cual sugiere que se favorecía su producción aislada de otros TM. 


\section{YGII: Combinaciones de TM por TU-p}

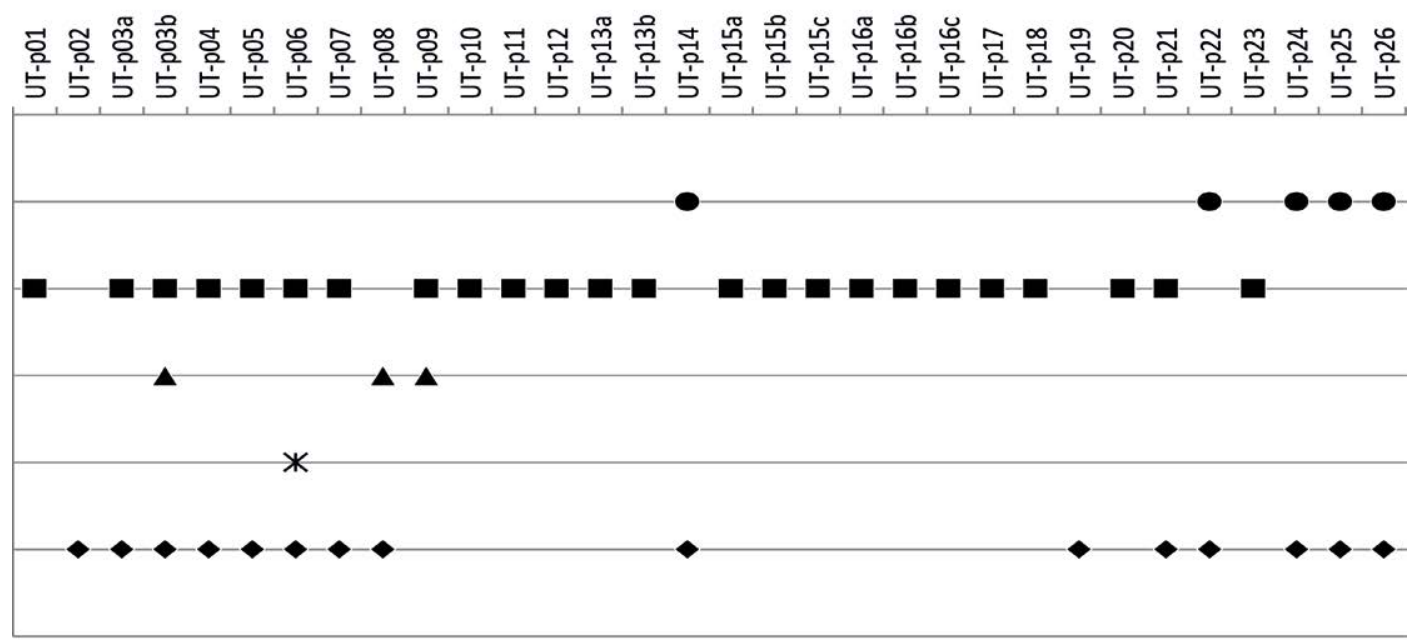

- circunferencias

- manos negativas

$\Delta$ manos positivas

* tridígitos

$\bullet$ otros

Figura 8. Presencia y combinación de TM (tipos de motivo) más relevantes en las UT de YGIl.

\section{YGIV: combinaciones de TM por UT-p}

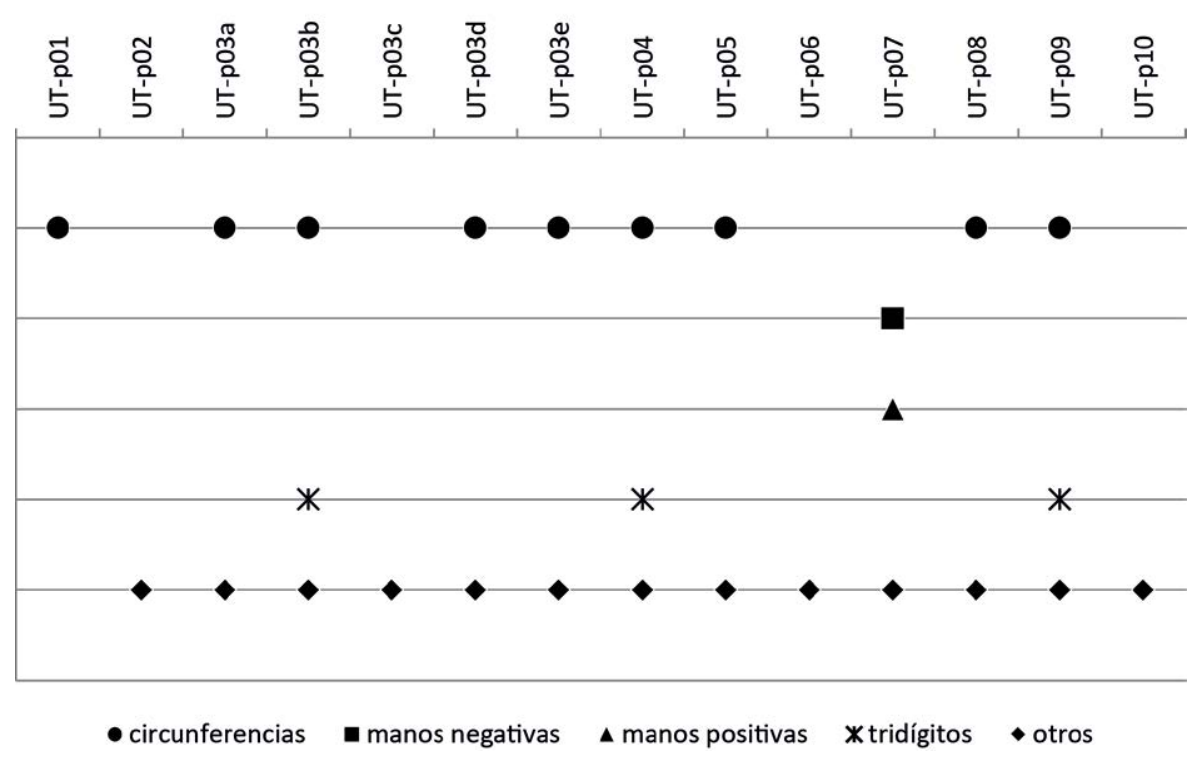

Figura 9. Presencia y combinación de TM (tipos de motivo) más relevantes en las UT de YGIV.

En el caso de YGIV, dado que esta transecta se caracteriza por la alta presencia de circunferencias (y no de negativos de mano), este hecho podría haber influido sobre las posibles reglas de composición allí registradas (Figura 9):

" las circunferencias (en nueve UT-p) nunca aparecen combinadas con las manos negativas, tal como ocurre en YGII; 
9. Interesantemente, esta regla de composición visual también ha sido observada en un sector del cañadón El Lechuza (Fiore y Ocampo, 2009), lo cual la amplía hacia otras zonas de la región MNRSC.
》 las circunferencias aparecen combinadas con otros TM en ocho de los nueve UT-p en los que han sido registradas, mostrando, tal como en YGII, que éstas eran proclives a formar parte de composiciones visuales más variadas, siendo así un TM más "permeable";

》 las manos negativas (en una UT-p) aparecen combinadas con las manos positivas (en la misma UT-p), tal como ocurre en YGII;

》 las manos negativas (en una UT-p) sí aparecen combinadas, además de las manos positivas, con otros TM, lo cual ocurre también en YGII pero como caso excepcional;

» los tridígitos (en tres UT-p) aparecen combinados con las circunferencias: aquí se observa una diferencia con YGII, ya que en esta última transecta el único caso de tridígito aparece combinado con manos negativas.

Estos resultados muestran la existencia de algunas similitudes compositivas entre YGII y YGIV, que se suman al dato arriba señalado, de que casi todo el repertorio de YGII (12 de 14 TM) está presente en YGIV (23 TM). Así, ambos sectores del cañadón comparten:

» la misma tendencia hacia combinar manos negativas y positivas;

" la misma tendencia hacia combinar circunferencias con otros TM, siendo aquellas el TM más versátil por ser proclive a diferentes tipos de combinaciones;

» la misma regla de exclusión -no combinación- entre manos negativas y circunferencias?.

Sin embargo, estos resultados también muestran la existencia de diferencias entre YGII y YGIV:

» en YGII las manos negativas se presentan más frecuentemente sin combinación con otros motivos, mientras que en YGIV el único caso de manos negativas está combinado con manos positivas y con otros TM;

» los tridígitos están combinados con el TM más frecuente de cada transecta, que son diferentes en cada una: manos negativas en YGII y circunferencias en YGIV, lo cual sugiere que este TM es permeable a combinaciones distintas y aparentemente vinculadas a las frecuencias diferenciales de los repertorios locales.

Finalmente, una tercera y fundamental aproximación al análisis univariado de los motivos que componen los paisajes rupestres es el estudio de las técnicas usadas para producirlos. Los casos de estudio aquí presentados muestran panoramas notablemente contrastantes. En YGII, del total de 206 motivos, 72,3\% fueron producidos con pintura positiva (incluyendo líneas rectas, circunferencias, puntos, óvalos, tridígitos, manos positivas, etc.), siendo el rojo el color más frecuente, seguido en muy baja frecuencia por el negro; $21,8 \%$ fueron producidos con pintura negativa (manos negativas), siendo el rojo el más frecuente, seguido por el blanco en menor proporción y 5,8\% fueron producidos mediante grabado piqueteado (piqueteado disperso, circunferencias, etc.). En YGIV, del total de 97 motivos, $74,2 \%$ fueron producidos mediante grabado piqueteado (incluyendo circunferencias, piqueteados dispersos, líneas curvas, tridígitos, líneas en $\mathrm{U}$, etc.); $17 \%$ fueron producidas mediante pintura positiva roja (líneas de puntos, líneas rectas, mano positiva); 7,2\% fueron producidas mediante grabados incisos (grafitis o marcas de ganado, cruz, reticulado, tridígito); y $1 \%$ mediante pintura negativa amarilla (mano negativa). Estos datos generan claros contrastes en las cualidades perceptibles al movilizarse a lo largo 
de cada paisaje rupestre. En YGII predomina la pintura, por lo cual la cualidad perceptual que resalta en este paisaje rupestre es el color, siendo el rojo el color más usado (tanto en pintura negativa como positiva) y en menor medida el negro, el blanco y el amarillo. Contrariamente, en YGIV predomina el grabado, por lo cual la cualidad perceptual principal de su paisaje rupestre es el contraste entre los distintos tonos de pátina y de texturas entre la roca soporte que se generan al remover parte de la superficie rocosa oscura, que, al grabarla, deja a la vista porciones más claras en las zonas piqueteadas o incisas. Así la textura de la roca grabada se regulariza pero varía según el tipo de técnica utilizada, volviéndose rugosa y con numerosos hoyuelos contiguos producto del piqueteado o volviéndose suave y netos surcos aguzados producto de la incisión.

La diferencia entre los paisajes rupestres de YGII y YGIV no puede ser atribuida a la distancia espacial de estos sectores respecto de las fuentes potenciales de pigmentos, ya que ambos se encuentran muy próximos entre sí -lo cual no explica el uso intensivo de técnicas de pintura en YGII- y ambos tienen la misma roca soporte -lo cual no favorece el uso intensivo de técnicas de grabado en YGIV-. Por lo tanto, podemos sugerir que las diferencias en estos paisajes rupestres responden a la acumulación de acciones antrópicas reiteradas con un mismo criterio técnico y estético a lo largo de cada sector del cañadón.

\section{Tendencias bivariadas a escala de motivo: tipos de motivos y técnicas de producción}

La caracterización de cada uno de los paisajes rupestres arriba analizados puede profundizarse al evaluar qué técnicas de producción artística han sido empleadas para producir determinados TM. Esta pregunta permite aproximarnos a identificar la versatilidad versus la inflexibilidad de la morfología de diseño de determinados TM respecto de su materialidad técnica: un TM versátil puede mantener su morfología y ser producido mediante numerosas técnicas, mientras que un TM inflexible mantiene un vínculo estrecho entre su morfología y su técnica de producción. Esto a su vez remite a numerosos factores subyacentes a la producción del TM, incluyendo desde limitaciones en el costo de inversión laboral hasta reglas estéticas de composición visual y de comunicación de información, que pueden haber influido sobre la versatilidad o inflexibilidad de los TM (Fiore, 2009).

En los sectores del cañadón Yaten Guajen bajo estudio, los 12 TM compartidos muestran tanto casos de TM inflexibles como casos versátiles. Las manos negativas y positivas han sido siempre ejecutadas con técnicas de pintura (con alta frecuencia en YGII y muy baja frecuencia en YGIV), lo cual es totalmente esperable dado que la propia morfología del motivo conlleva la técnica de ejecución ${ }^{10}$, resultando así ser TMs claramente inflexibles ${ }^{11}$. Las líneas rectas aparecen, en ambas transectas, mayoritariamente producidas mediante técnica de pintura positiva roja, indicando su baja versatilidad. Contrariamente, las circunferencias, las líneas curvas, los puntos, los tridígitos y los óvalos han sido producidos con pintura en YGII y con grabado en YGIV, lo cual permite inferir que éstos TM son comparativamente más versátiles respecto de su materialidad tecnológica. Estos resultados enfatizan que en cada sector del cañadón predominaba una forma técnica de hacer imágenes: seis de los TM compartidos se produjeron con técnicas distintas. Así, de los dos aspectos de la materialidad del motivo, su diseño se mantuvo mientras que su técnica fue variada. Esto sugiere que posiblemente los diseños circularon a lo largo de estos sectores del cañadón más allá de las variaciones técnicas porque sus morfologías acarreaban información, significados simbólicos y/o valores estéticos que requerían algún grado de estandarización morfológica (otros casos similares han sido discutidos en Fiore, 2006).
10. Existen casos de manos positivas grabadas, por ejemplo, en un sector del Cañadón Mercerá en la misma región MNRSC (Fiore y Ocampo, 2009), lo cual demuestra que es posible -pero extremadamente poco frecuentela producción de este TM con técnicas "no convencionales" como el piqueteado en vez de la pintura.

11. A su vez, las marcas de ganado aparecen siempre producidas mediante técnicas de grabado inciso, pero como se las registró solamente en YGIV, la comparación con YGll para evaluar su potencial versatilidad técnica no es viable. 
12. Un test de $x^{2}$ para las variables NM y NTM demuestra que éstas mantienen una relación estadísticamente significativa $\left(\mathrm{x}^{2}\right.$ $=8,82 ; \mathrm{df}=1 ;$ Pval = 0,0030; $99 \%$ grado de confianza), lo cual implica que el vínculo entre la frecuencia de motivos y de tipos de motivos no es azarosa ni depende del tamaño de la muestra.

\section{Discusión y comentarios finales: arte, percepción y movimiento en los paisajes rupestres}

En este trabajo nos hemos propuesto caracterizar de manera sistemática y exploratoria varios elementos que subyacen a la creación de paisajes rupestres mediante el emplazamiento de imágenes de arte rupestre sobre dos sectores del cañadón Yaten Guajen, cuyo registro se ha efectuado mediante transectas con el objeto de explorar e identificar patrones relacionales y no-relacionales de vínculo entre motivos y soportes y de motivos entre sí. Estos paisajes rupestres tienen rasgos diferenciales a distintas escalas espaciales, complementarias entre sí (Fiore, 2016). A escala de la transecta se ha registrado que YGII, que se encuentra en un sector del cañadón más acotado, encajonado y rectilíneo, es más corta, tiene una mayor cantidad de UTs con arte y una mayor cantidad de motivos rupestres, pero sin embargo registra un menor NTM (número de tipos de motivos), es decir, su repertorio es más pequeño y menos variado. Contrariamente, YGIV, que se encuentra en un sector del cañadón más amplio y curvo, es una transecta más larga, tiene un menor número de UTs con arte y un menor número de motivos rupestres, pero tiene un mayor NTM, que implica un repertorio más rico y variado.

En otras palabras, el paisaje rupestre de YGII tiene mayor densidad de arte medido según el N de UT con arte, mayor frecuencia de motivos rupestres y menor variabilidad de repertorio, que no depende ni de la oferta de las UT donde emplazar el arte, ni de la cantidad de motivos de arte producidos. Contrariamente, el paisaje rupestre de YGIV, a pesar de ser espacialmente más amplio, tiene una menor densidad de arte rupestre y una menor frecuencia de motivos, pero a su vez tiene una mayor variabilidad de repertorio (que tampoco puede ser atribuido al tamaño de la muestra ${ }^{12}$ ). A su vez, estas diferencias no parecen atribuibles de manera directa a problemas de preservación, ya que las frecuencias más altas de motivos corresponden a pinturas, las cuales, habiendo sido producidas en sectores contiguos, sobre la misma roca soporte y estando bajo las mismas condiciones ambientales generales, son comparativamente más proclives al deterioro que los grabados (Bednarik, 2001; Fiore, 2006; Rosenfeld, 1988).

Respecto de los tipos de topografía del soporte rocoso que conforman parte sustancial del paisaje rupestre, en YGII las imágenes rupestres se emplazaron prioritariamente en abrigos, mientras que en YGIV hay un uso más balanceado de abrigos y paredones. Hasta cierto punto, esta leve diferencia podría estar relacionada con las técnicas de producción mayormente empleadas en cada sector del cañadón, ya que dado el uso prioritario de pintura en YGII hace esperable que su emplazamiento sea en topografías que ofrecen cierto reparo -como los abrigos y cuevas- mientras que el uso de paredones habría sido o bien menos elegible o bien no habría ofrecido reparo suficiente y habría facilitado la obliteración e incluso desaparición de motivos pintados (la presencia de ocho manchas de pintura provee evidencia significativa en este sentido). A su vez, el uso prioritario del grabado en YGIV hace esperable que el emplazamiento de motivos esté repartido entre abrigos y paredones, ya que la perdurabilidad del grabado es comparativamente mayor que la de la pintura rupestre.

La expansión y frecuencia de las técnicas de producción es también un rasgo esencial del paisaje rupestre: en YGII la pintura es la técnica más expandida (en $92 \%$ de las UT) y la más frecuentemente usada (en 94\% de los motivos) mientras que en YGIV el grabado es la técnica más expandida (en $80 \%$ de las UT) y la más frecuentemente usada (en $74,2 \%$ de los motivos). Esto implica que el uso repetido y consistente de un grupo de técnicas - pintura o grabado- en cada sector del cañadón habría ofrecido una importante unicidad al paisaje rupestre de cada sector y un marcado contraste entre sectores. Tanto la unicidad intra-sector como el contraste inter-sectores se habrían percibido mediante el desplazamiento y visualización de las paredes a lo largo del cañadón (ver más abajo). 
Respecto de la composición de las imágenes en las UT, resulta claro que el TM más expandido y más frecuente en YGII son las manos negativas (pintadas), mientras que en YGIV son las circunferencias (grabadas). A su vez, YGII, que tiene más UT con arte, mayor frecuencia de motivos y menor repertorio, registra:

a) casi la misma proporción de UTs con un solo motivo y UTs con varios motivos;

b) casi la misma proporción entre UTs con solo un TM y UTs con varios TM;

c) un máximo de cuatro TMs (sobre 12) combinados en la misma UT; lo cual sugiere una tendencia hacia la creación de composiciones visuales con una variabilidad más bien baja.

Contrastando con ésto, YGIV, que tiene menos UT con arte, menor frecuencia de motivos pero mayor repertorio, registra:

a) un claro predominio de UTs con varios motivos emplazados juntos;

b) un claro predominio de UTs con varios TMs combinados;

c) un máximo de 11 TMs (sobre 23) combinados en la misma UT; lo cual sugiere una tendencia hacia la creación de composiciones visuales con una variabilidad más bien alta.

Sin embargo, hemos notado que en ambas transectas, los TM más frecuentes -manos negativas en YGII y circunferencias en YGIV- nunca aparecen combinados en la misma UT-p, señalando así una aparente regla de exclusión o no-combinación en ambos sectores del cañadón Yaten Guajen, marcando una similitud subyacente a la construcción de sus paisajes rupestres.

Estos paisajes rupestres solamente habrían sido visualmente perceptibles al recorrer el cañadón, actividad totalmente esperable dentro de los hábitos de movilidad de poblaciones cazadores-recolectores de Patagonia y coincidente con la alta circulación de grupos inferida para el cañadón a partir de las características el registro arqueológico de superficie y excavado: la realización de actividades específicas y efímeras, con baja redundancia ocupacional de sitios debido a la alta oferta de reparos disponibles (Cirigliano, 2016; Franco et al., 2014). El propio movimiento generado por dichas actividades podría incluso haber estimulado la circulación de los productores de las imágenes rupestres a lo largo del cañadón, a la vez que las imágenes, una vez emplazadas, podrían haber estimulado la re-visita de distintos sectores del cañadón. Allí, de manera consistente, se eligió producir motivos manteniendo de forma cuasi-homogénea el uso de una determinada técnica rupestre (grabado o pintura). Así, el emplazamiento inicial de las imágenes habría generado un efecto atractor sobre futuras producciones rupestres, que a su vez parecen haber estado parcialmente condicionadas por la materialidad técnica y visual de las imágenes previas: este parece ser un interesante ejemplo de la cualidad estructurada y estructurante de la agencia humana y de las imágenes artísticas por ella producidas (Gell, 1998), ya que su influencia orientativa sobre futuras creaciones artísticas no requiere necesariamente de la co-presencia de distintos productores, sino que basta con observar las imágenes plasmadas en el soporte para hacer algo distinto o repetirlas, como se observa en estos casos.

La interacción con dichas imágenes no habría sido en absoluto mecánica, sino que la elección de continuar o no con el uso de una u otra técnica rupestre debe haber estado mediada necesariamente tanto por factores económicos y tecnológicos (disponibilidad de materiales, instrumentos y conocimiento, costos relativos de obtención de cada 
material, inversión laboral requerida por el uso de cada técnica para producir cada tipo de motivo sobre el soporte, etc.) como por factores simbólicos (ej. significados de cada tipo de motivo y cada técnica), estéticos (ej. sensaciones vinculadas a cada efecto visual, generado por la morfología del motivo y las cualidades de la técnica) y visuales (ej. contraste y textura generados por cada técnica). Dado que: a) los casos bajo estudio están conformados por el mismo tipo de soporte rocoso -basaltos con semejantes cualidades de dureza y coloración- y que b) los sectores analizados se encuentran próximos entre sí -por lo cual las distancias de transporte de materias primas e instrumentos no son limitantes para el uso de una u otra técnica-; los factores económicos relativos a los costos de obtención y traslado de materiales y la inversión laboral en la producción de imágenes con distintas técnicas no parecen haber sido los principales causantes de la profunda diferenciación inter-sectores documentada en este trabajo. Por lo tanto, es más asequible sugerir que los factores de mayor peso en estos casos serían los simbólicos, estéticos y visuales, que cualifican a las distintas técnicas y a los motivos producidos con ellas. En tal sentido, el alto contraste visual generado en YGII mediante el uso de pintura -en su mayoría roja, seguida por negro y blanco- difiere marcadamente del contraste visual generado en YGIV por los grabados -en su mayoría piqueteados-, ya que este último es comparativamente menor porque depende de la forma de insolación que reciban los grabados en distintos momentos del día. A su vez, respecto de la textura -tanto visual como táctil-, en YGII la textura de las pinturas es comparativamente suave y homogénea en comparación con la textura de YGIV generada por los grabados -en su mayoría piqueteados-, que es considerablemente rugosa. Así, en YGII, donde predominan las manos negativas, el vínculo entre productor y roca habría estado primordialmente mediado por su propia mano apoyada en el soporte (Ouzman, 1998), mientras que en YGIV habría estado mediado por sus instrumentos de grabado: este contraste en el propio acto de producción posiblemente le haya dado parte de su sentido a las imágenes resultantes, influyendo así en la continuidad del uso de cada técnica en cada sector.

Pese a estas diferencias, se ha registrado que no solo $12 \mathrm{TM}$ se comparten entre ambas transectas, sino que seis de ellos (circunferencias, líneas curvas, puntos, óvalos, tridígitos y antropomorfos) han sido producidos con la técnica más frecuentemente usada en cada sector del cañadón. Las imágenes tienen una mayor variabilidad intrínseca potencial en su diseño que en sus técnicas, ya que éstas tienen mayores restricciones materiales y por lo tanto menor variabilidad intrínseca potencial (Fiore, 2007, 2009, 2011). Esto implica que siempre es más esperable hallar un rango mayor de diseños de motivos que de técnicas de producción, tendencia que se comprueba en ambas transectas. Sin embargo, los seis casos arriba señalados desafían esta expectativa, porque los mismos TM han sido producidos mediante distintas técnicas rupestres según en qué sector del cañadón se hayan creado. Así, los productores de estos TM han mantenido su morfología, debido a que posiblemente la estandarización de su diseño haya respondido a reglas estéticas y/o de comunicación visual de información, pero han variado su materialidad tecnológica, adaptándola a la técnica más frecuentemente usada en cada sector del cañadón, mostrando su versatilidad. Esta "forma de hacer las cosas" fue repetida dentro de cada sector, contribuyendo así a la construcción de cada paisaje rupestre. Esto resulta particularmente relevante ya que sugiere la existencia de ciertas formas de orientación social de la creación artística, dentro de contextos cazadores-recolectores.

Contrariamente, hay tipos de motivos que han sido ejecutados siempre con la misma técnica, a pesar de que no sea la más frecuentemente utilizada en cada sector: los negativos y positivos de mano, los piqueteados dispersos (sin morfología aparente) y los grafitis/marcas de ganado. Estos tipos de motivo parecen haber implicado un vínculo más sólido entre morfología y tecnología, mostrando menor flexibilidad en su materialidad técnica. En los casos de las manos, ello posiblemente se deba a cuestiones relativas a la mayor facilidad tecnológica de producción de éstas mediante técnicas de 
pintura negativa y positiva, así como también a que dichas técnicas habilitan el apoyo de la palma sobre el soporte, implicando un contacto directo entre persona y roca que no habría ocurrido si hubieran sido grabadas. En el caso de los grafitis/marcas de ganado, de datación relativa más reciente, el uso de técnicas de grabado posiblemente se deba a cuestiones de mayor disponibilidad de instrumentos adaptables a operaciones extractivas de la roca soporte (tanto para piqueteo como para incisión). En el caso de los piqueteados dispersos, es posible -aunque no comprobable- que parte del propósito de la ejecución de estas marcas grabadas haya sido auditivo -i.e. escuchar el sonido del golpe del percutor sobre la roca- y no solo visual (Ouzman, 1998).

En síntesis, la percepción visual del paisaje rupestre habría estado directamente ligada al movimiento del observador. La percepción tradicional de las obras de arte pictórico occidental (pinturas, grabados, dibujos, etc.) es distinta, ya que generalmente están diseñadas para ser observadas desde un único punto de vista y requieren que el observador permanezca estático frente a la obra -o a lo sumo se desplace levemente a lo largo de un eje perpendicular a la obra, en un movimiento de aproximación para observar detalles y alejamiento para contemplar la obra completa- (Arnheim, 1956; Gombrich, 1984). La percepción visual de algunos paneles con arte rupestre bien puede haber incluido este tipo de observación inmóvil y contemplativa, pero el movimiento habría sido una condición esencial para la percepción de los paisajes rupestres, porque solo a través del desplazamiento a lo largo de amplios sectores del soporte rocoso podría haber sido posible visualizar los conjuntos de imágenes allí emplazadas. La metodología aquí empleada busca sistematizar el registro y análisis de las continuidades y cambios subyacentes a la construcción de estos paisajes rupestres y no pretende ser una aproximación directa ni análoga a las formas de percepción de estos paisajes en el pasado. Los resultados de su aplicación en el cañadón Yaten Guajen sugieren que existieron formas de hacer arte recurrentes en determinados sectores del espacio y que la percepción visual de los distintos paisajes resultantes habría estado directamente vinculada no solo con el mirar y ver, sino con el caminar y recorrer. Así, las imágenes rupestres del cañadón Yaten Guajen no solo resultan marcas de la agencia social acumulada de las poblaciones que lo circularon y habitaron en el pasado, sino que también condensan y expresan parte de esa agencia en el presente, estimulando a los observadores actuales a moverse para mirar y a detenerse para ver. Todas estas prácticas de acción y experiencia entre rocas, imágenes y personas, habrían conformado la construcción de paisajes en el mundo cazador-recolector de Patagonia en el pasado: esos paisajes invitan a la percepción y el movimiento aún en el presente.

\section{Agradecimientos}

Los trabajos de campo fueron realizados con apoyo de los siguientes subsidios: PIP $11220120100447 \mathrm{CO}$ (otorgado por CONICET) y UBACyT 20020130100664BA (otorgado por UBA) dirigidos por la Dra. Nora Franco. Agradecemos también a todos los colegas que participaron en los trabajos de campo (especialmente a la Prof. Mariana Ocampo). A la familia Hudson de estancia Yaten Guajen. A la Dra. Debora Kligmann por su dedicada labor editorial y a los evaluadores/as por sus valiosos comentarios. 


\section{Q Referencias citadas}

» Acevedo, A., Fiore, D. y Franco, N. V. (2013). Imágenes en las rocas: uso del espacio y construcción del paisaje mediante el emplazamiento de arte rupestre en dos regiones de Patagonia centro-meridional (Argentina). Espacio, Tiempo y Forma, 6, 17-53.

"Acevedo, A., Fiore, D., Franco, N. V. y Ocampo M. (2012-2014). Arte y espacio. Estructuración de los repertorios de arte rupestre en los cañadones Yaten Guajen y El Lechuza (Margen Norte del Río Santa Cruz, Patagonia, Argentina). Mundo de Antes, 8 , 9-33.

"Anschuetz, K., Wilshusen, R. y Scheick, C. (2001). An archaeology of landscapes: perspectives and directions. Journal of Archaeological Research, 9(2), 157-211.

"Arnheim, R. (1956). Art and visual perception. A psychology of the creative eye. Londres: Faber \& Faber Ltd.

" Aschero, C. (1988). Pinturas rupestres, actividades y recursos naturales, un encuadre arqueológico. En H. Yacobaccio (Ed.), Arqueología Contemporánea Argentina (pp. 51-69). Buenos Aires: Búsqueda.

» Aschero, C. (1997). De cómo interactúan emplazamientos, conjuntos y temas. Actas y Memorias del XI Congreso Nacional de Arqueología Argentina. Revista del Historia Natural de San Rafael, 13(1/4), 17-28.

" Aschero, C. y Martel, A. (2003-2005). El arte rupestre de Curuto-5. Antofagasta de la Sierra (Catamarca, Argentina). Cuadernos del Instituto Nacional de Antropología y Pensamiento Latinoamericano, 20, 47-72.

» Bednarik, R. (2001). Rock art science. The scientific study of Palaeoart. Turnhout: Brepols.

»Bourdieu, P. (1977). Outline of a Theory of Practice. Cambridge: Cambridge University Press.

» Bradley, R., Criado Boado, F. y Fabregas Valcarce, R. (1994). Rock art research as landscape archaeology: a pilot study in Galicia, north-west Spain. World Archaeology, 25(3), 374-390.

» Burmeister, C. V. (1892). Nuevos datos sobre el Territorio Patagónico de Santa Cruz. Revista del Museo de La Plata, IV, 221-256.

" Butzer, C. (1982). Archaeology as human ecology. Cambridge: Cambridge University Press.

"Carden, N. (2008). Imágenes a través del tiempo: arte rupestre y construcción social del paisaje en la Meseta Central de Santa Cruz. Ciudad Autónoma de Buenos Aires: Sociedad Argentina de Antropología.

»Cirigliano, N. A. (2016). A través de sendas y caminos: un estudio sobre los cambios en la circulación y movilidad humana entre las cuencas de los ríos Chico -curso inferior y medioy Santa Cruz durante los últimos 2000 años (Provincia de Santa Cruz, Argentina). (Tesis Doctoral inédita), Universidad de Buenos Aires, Argentina.

"Conkey, M. (1984). To find ourselves: art and social geography of prehistoric huntergatheres. En M. Shire (Ed.), Past and Present in Hunter Gatherer Studies (pp. 253-276). Nueva York: Academic Press.

»Criado Boado, F. y Penedo Romero, R. (1989). Cazadores y salvajes: una contraposición entre el arte Paleolítico y el arte Postglacial levantino. Munibe Antropología-Arkeologia, 41, 3-22. 
»Dobres, M. A. (2000). Technology and Social Agency: Outlining Practice Theory for Archaeology. Malden: Blackwell Publishers.

»Domingo Sanz, I., Fiore, D. y May, S. (Eds.). (2008). Archaeologies of art. Time, place and identity. One World Archaeology 55. California: Left Coast Press.

» Dunnell, R. y Dancey, W. (1983). The siteless survey: a regional scale data collection strategy. En M. Schiffer (Ed.), Advances in Archaeological Method and Theory (pp. 267-287). Nueva York: Academic Press.

» Fiore, D. (2006). Poblamiento de imágenes: arte rupestre y colonización de la Patagonia. Variabilidad y ritmos de cambio en tiempo y espacio. En D. Fiore y M. Podestá (Eds.), Tramas en la Piedra. Producción y usos del arte rupestre (pp. 43-61). Buenos Aires: World Archaeological Congress (WAC) - Asociación de Amigos del Instituto Nacional de Antropología (AINA) - Sociedad Argentina de Antropología.

»Fiore, D. (2007). The economic side of rock art. Concepts on the production of visual images. Rock Art Research, 24(2), 149-160.

»Fiore, D. (2009). La materialidad del arte. Modelos económicos, tecnológicos y cognitivovisuales. En R. Barberena, K. Borrazo y L. A. Borrero (Eds.), Perspectivas Actuales en Arqueología Argentina (pp. 121-154). Buenos Aires: Instituto Multidisciplinario de Historia y Ciencias Humanas (IMHICIHU), CONICET.

» Fiore, D. (2011). Art in time. Diachronic rates of change in the decoration of bone artefacts from the Beagle Channel region (Tierra del Fuego, Southern South America). Journal of Anthropological Archaeology, 30, 484-501.

» Fiore, D. (2016). Las dimensiones espaciales del arte parietal. Estado actual de las investigaciones desde el Cono Sur y propuesta de síntesis metodológica. En A. M. Rocchietti, F. Oliva y F. Solomita (Eds.), Imagenes Rupestres: Lugares y Regiones (pp. 5162). Rosario: Centro de Estudios Arqueológicos regionales (CEAR) y Centro de Estudios del Ambiente Humano (CEAH).

»Fiore, D. y Acevedo, A. (2016). El Trabajo del arte. Una evaluación de la inversión laboral en la producción de arte rupestre: el caso del Cañadón Yaten Guajen (Santa Cruz, Patagonia, Argentina). En A. M. Rocchietti, F. Oliva y F. Solomita (Eds.), Imagenes Rupestres: Lugares y Regiones (pp. 485-504). Rosario: Centro de Estudios Arqueológicos regionales (CEAR) y Centro de Estudios del Ambiente Humano (CEAH).

»Fiore, D. y Ocampo, M. (2009). Arte rupestre de la región Margen Norte del Río Santa Cruz: una perspectiva distribucional. En M. Salemme, F. Santiago, M. Álvarez, E. Piana, M. Vázquez y M. Mansur (Eds.), Arqueología de Patagonia: una mirada desde el último confín (pp. 499-513). Ushuaia: Utopías.

» Foley, R. (1981). Off-site archaeology: an alternative approach for the short-sited. En I. Hodder, G. Isaac y N. Hammond (Eds.), Patterns of the past (pp. 157-183). Cambridge: Cambridge University Press.

» Franco, N. (2008). La estructura tecnológica regional y la comprensión de la movilidad humana: tendencias para la cuenca del río Santa Cruz. En L. A. Borrero y N. V. Franco (Eds.), Arqueología del extremo sur del continente americano. Resultados de nuevos proyectos (pp. 119-154). Buenos Aires: Instituto Multidisciplinario de Historia y Ciencias Humanas (IMIHICIHU), CONICET.

» Franco, N. (2012). ¿Es posible diferenciar la existencia de grupos con áreas de circulación distintas en el extremo sur de Patagonia durante el Holoceno tardío? En A. F. Zangrando, R. Barberena, A. Gil, G. Neme, M. Giardina, L. Luna, C. Otaola, S. Paulides, L. Salgán y A. Tívoli (Eds.), Tendencias teórico-metodológicas y casos de estudio en la arqueología de Patagonia (pp. 363-370). San Rafael: Museo de Historia Natural de San Rafael - Instituto Nacional de Antropología y Pensamiento Latinoamericano - Sociedad Argentina de Antropología. 
» Franco, N. V., Cardillo, M.y Otaola, C. (2007). Resultados de los trabajos exploratorios realizados en la margen norte del río Santa Cruz (provincia de Santa Cruz, Argentina). En F. Morillo, M. Martinic, A. Prieto y G. Bahamonde (Eds.), Arqueología de Fuego-Patagonia. Levantando piedras, desenterrando huesos... y develando arcanos (pp. 541-553). Punta Arenas: Ediciones CEQUA.

»Franco, N. V., Cirigliano, N. A., Fiore, D., Ocampo, M. y Acevedo, A. (2014). Las ocupaciones del Holoceno tardío en los cañadones basálticos del norte del río Santa Cruz (Patagonia, Argentina). Intersecciones en Antropología, 15, 377-389.

" Gell, A. (1998). Art and agency. An anthropological theory. Oxford: Clarendon Press.

" Giddens, A. (1979). Central Problems in Social Theory: Action, Structure and Contradiction in Social Analysis. Londres: Macmillan.

" Gkiasta, M. (2008). Historiography of landscape research on Crete. Amsterdam: Leiden University Press.

"Gombrich, E. (1984). The sense of order. A study in the psychology of decorative art. Londres: Phaidon.

»Gradin, C. J. (1978). Algunos aspectos del análisis de las manifestaciones rupestres. Revista del Museo Provincial de Neuquén, 1, 120-133.

»Gradin, C. J. (1988). Caracterización de las tendencias estilísticas del arte rupestre de la Patagonia (provincias de Río Negro, Chubut y Santa Cruz, República Argentina). Nuevos estudios del arte rupestre argentino. Contribuciones al estudio del arte sudamericano. Boletín de la Sociedad de Investigación del Arte Rupestre de Bolivia (SIARB), 2, 54-67.

"Gradin, C. J. (2000). Más allá y más acá del río Santa Cruz. Buenos Aires: Talleres Gráficos Nuevo FOCET.

" Gradin, C. J. (2001). El arte rupestre de los cazadores de guanaco de la Patagonia. En E. Berberián y A. Nielsen (Eds.), Historia Argentina Prehispánica (pp. 839-873). Córdoba: Brujas.

»Gradin, C. J., Aschero C. y Aguerre, A. (1979). Arqueología del área río Pinturas. Relaciones de la Sociedad Argentina de Antropología, XIII, 183-227.

» Hernández Llosas, M. I. (2009). Rock art research and beyond. Archaeological inquiry, political responsibility and community involvement in the process of protecting and presenting rock art sites. En L'Art Parietal: conservation, mise en valeur, communication, Actes du colloque international des Eyzies-de-Tayac (pp. 63-76). Les Eyzies: SAMRA.

»Ingold, T. (1986). The Appropriation of Nature: Essays on Human Ecology and Social Relationships. Manchester: Manchester University Press.

" Jochim, M. (1983). Palaeolithic cave art in ecological perspective. En G. Bailey (Ed.), Hunter-gatherer economy in prehistory. New Directions in Archaeology (pp. 212-219). Cambridge: Cambridge University Press.

"Leroi-Gourhan, A. (1967). Treasures of prehistoric art. Nueva York: Harry Abrams.

» Loendorf, L. (2001). Rock art recording. En D. Whitley (Ed.), Handbook of Rock Art Research (pp. 55-79). Oxford: AltaMira Press.

»Menghin, O. (1957). Los estilos del arte rupestre de Patagonia. Acta Prehistórica, 1, 57-87.

» Molina, M. (1971). Arqueología patagónica - arte rupestre austral. Antiquitas, 12-13, 24-30.

» Molina, M. (1972). Nuevos aportes para el estudio del arte rupestre patagónico. Anales de la Universidad de la Patagonia San Juan Bosco, 1(2), 64-182.

» Ouzman, S. (1998). Towards a mindscape of landscape: rock-art as expression of worldunderstanding. En C. Chippindale y P. Taçon (Eds.), The Archaeology of Rock-Art (pp. 30-41). Cambridge: Cambridge University Press. 
»Panza, L. y Franchi, M. R. (2002). Magmatismo basáltico cenozoico extraordinario. En M. J. Haller (Ed.), Relatorio XV Congreso Geológico Argentino: geología y recursos naturales de Santa Cruz (pp. 201-236). Buenos Aires: Asociación Geológica Argentina.

» Parcero Oubiña, C., Criado Boado, F. y Barreiro, D. (2014). Landscape Archaeology. En C. Smith (Ed.), Encyclopaedia of Global Archaeology (pp. 4379-4388). Heidelberg: Springer.

» Re, A. (2010). Representaciones rupestres en mesetas altas de la provincia de Santa Cruz. Circulación de información en espacios de uso estacional. (Tesis Doctoral inédita), Universidad de Buenos Aires, Argentina.

» Re, A., Cassiodoro, G., Guichón, F., Flores Coni, J., Dellepiane, J. y Goñi, R. (2016). Sello arqueológico sobre grabados en la meseta del Guitarra (Santa Cruz-Argentina). Magallania, 44(1), 259-266.

» Rosenfeld, A. (1988). Rock art conservation in Australia. Canberra: Australian Government Publishing Service.

"Schaafsma, P. (1985). Form, content and function: theory and method in North American rock art studies. Advances in Archaeological Method and Theory, 8, 237-277.

» Tilley, C. (1991). The art of ambiguity. Cambridge: Cambridge University Press.

» Tilley, C. (1994). A phenomenology of landscape: places, paths and monuments. Oxford: Berg.

» Tilley, C. y Bennett, W. (2012). Body and Image: Explorations in Landscape Phenomenology 2. Walnut Creek: Left Coast Press.

» Vita Finzi, C. y Higgs, E. (1970). Prehistoric economy of the Mount Carmel Area of Palestine: site catchment analysis. Proceedings of Prehistoric Society, 36, 1-37.

»Willey, G. y Phillips, P. (1958). Method and theory in American archaeology. Chicago: University of Chicago Press. 